\title{
Characterization of Solids Collected from H-Area Injection Wells and Injection Tank Chemistry from both F- and H-Area Water Treatment Units (WTUs)
}

by

S. M. Serkiz

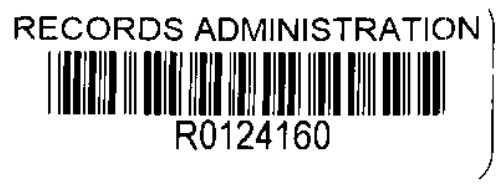

Westinghouse Savannah River Company

Savannah River Site

Aiken, South Carolina 29808

J. Thibault

This paper was prepared in connection with work done under the above contract number with the U.S. Department of Energy. By acceptance of this paper, the publisher and/or recipient acknowledges the U.S. Government's right to retain a nonexclusive, royalty-free license in and to any copyright covering this paper, along with the right to reproduce and to authorize others to reproduce all or part of the copyrighted paper. 


\section{DISCLAIMER}

This report was prepared as an account of work sponsored by an agency of the United States Government. Neither the United States Government nor any agency thereof, nor any of their employees, makes any warranty, express or implied, or assumes any legal liability or responsibility for the accuracy, completeness, or usefulness of any information, apparatus, product, or process disclosed, or represents that its use would not infringe privately owned rights. Reference herein to any specific commercial product, process, or service by trade name, trademark, manufacturer, or otherwise does not necessarily constitute or imply its endorsement, recommendation, or favoring by the United States Government or any agency thereof. The views and opinions of authors expressed herein do not necessarily state or reflect those of the United States Government or any agency thereof.

This report has been reproduced directly from the best available copy.

Available to DOE and DOE contractors from the Office of Scientific and Technical Information, P.O. Box 62, Oak Ridge, TN 37831; prices available from (615) 576-8401.

Available to the public from the National Technical Information Service, U.S. Department of Commerce, 5285 Port Royal Road, Springfield, VA 22161. 
Rev. 0

\author{
Characterization of Solids Collected from H-Area \\ Injection Wells and Injection Tank Chemistry \\ from Both F- and H-Area Water Treatment Units (WTUs)
}

December 3, 1998

Westinghouse Savannah River Company

Aiken, SC 29808

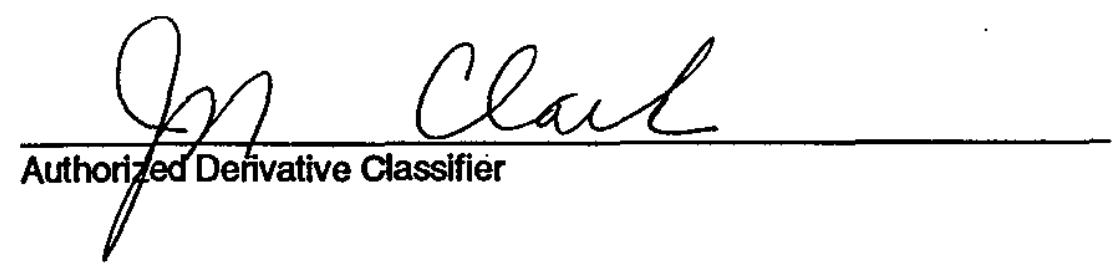

Authors
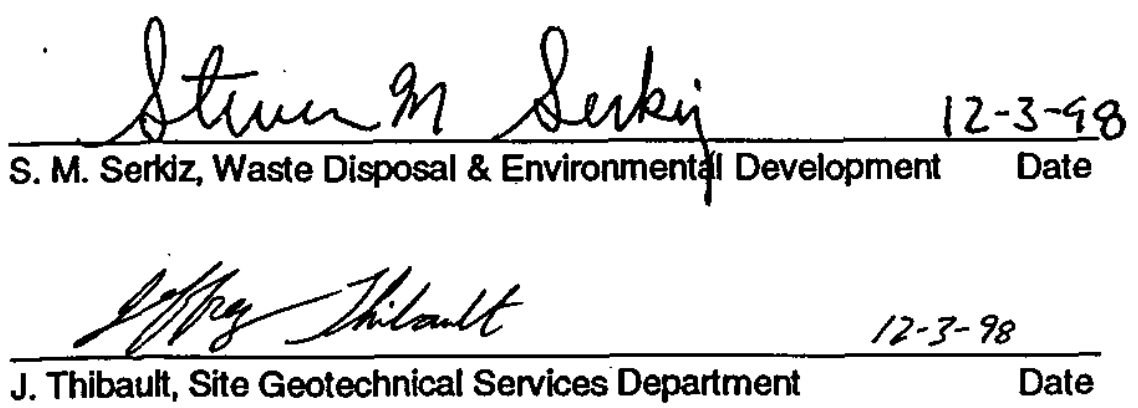


\subsection{Executive Summary}

Injection capacity at both of the F- and H-Area Seepage Basins Groundwater Remediation systems has been observed to decline since startup and operation of the facilities. Concern has been raised that if injection capacity reduction continues, the current injection well fields may not be capable of supporting operation of these systems at the permitted design flow rates. To address this concern, solids were collected from the injection wells at $\mathrm{H}$ Area Seepage Basins during the last period of well redevelopment and analyzed to investigate possible sources of well deterioration.

Characterization of the injection well solids revealed that fiberglass fibers, PVC fragments, and other debris were present in the injection wells. Also noted was a soft gelatinous material that formed a discontinuous coating on both the inside and outside of the injection piping and was present in the discharge water from development of the injection wells. This material may contribute significantly to physical blocking of the well. Mineralogical characterization of injection well solids identified a variety of solid phases including amorphous silica material, clay/micaceous minerals, metal oxyhydroxides, quartz, and zeolite. Of the minerals identified during these experiments it is thought that the montmorillonite (from the bentonite chemistry), zeolite (from the polishing columns), and metal oxy-hydroxides/amorphous material (from the neutralization process) could be have been added directly to the wells from the WTU. A definitive mass contribution of these materials due to the process chemistry of the WTU could not be determined based on existing data because these mineral phases are typically present in native aquifer water at the SRS. Additional sampling would be required to make this determination.

Injection tank water characterization in both $\mathrm{F}$ - and $\mathrm{H}$ Areas identified significantly elevated (based on influent water concentrations) concentrations of organic carbon which are suggestive of microbiological activity. Also noted were elevated concentrations of sulfate, a potential nutrient source for microbes, and an anion capable of precipitating calcium as gypsum.

Injection and/or precipitation of gypsum in the aquifer could produce significant aquifer clogging. Under conditions of high calcium and sulfate concentrations the precipitation is unavoidable. Therefore, efforts should be made to reduce the addition of calcium and sulfate to avoid or minimize this problem. F-Area injection water contains high suspended solids and aluminum concentrations that may also contribute to injection well clogging.

This study suggests that a strong potential exists for both chemical and biological fouling of the injection wells at the F- and $\mathrm{H}$ Area remediation systems. To further evaluate the potential, an evaluation of WTU process chemistry, characterization of the natural groundwater geochemistry, and analysis of microbiological activity should be performed.

\subsection{Introduction and Objectives}

A RCRA Part B permit between the South Carolina Department of Environmental Control (SCDHEC) and the SRS prescribes a Phase I pump-treat-reinject remediation strategy for contaminated groundwater at the F- and H Area Seepage Basins. Concerns have previously been raised over the long-term performance of injection wells associated with this system (Sadler, 1994, Maryak and Day, 1997). Specifically, injection well performance has been observed to deteriorate during startup and operation of the remediation systems. This problem is more significant at H-Area.

Degradation of well performance can be caused by a variety of mechanisms including physical, chemical, and biological processes. The processes that are potentially reducing injection well performance at the $F-$ and $H$ Area Groundwater Remediation units include chemical precipitation in the well and aquifer, colloidal mobilization in the aquifer, direct injection of solids, and biological growth.

As part of general well maintenance, the injection wells are redeveloped periodically to improve injection capacity. During the most recent well redevelopment in the spring of 1998, data were collected on the quantity and nature of solids that were found in injection wells at the H-Area Groundwater Remediation system. Specifically, the following characterization techniques were employed:

1. Photographic documentation of solids found in the injection wells;

2. Mineralogical characterization of the clay-size solids found in the injection wells using X-ray diffraction analysis; and

3. Characterization of treated water and suspended solids collected in grab samples from the injection tanks from both the F- and H Area water treatment units (WTUs) as a possible source of solids observed in the system injection wells.

This report summarizes the results of this activity.

\subsection{Methods and Materials}

This section describes the approach and techniques used to characterize the injection water chemistry and the solid material collected from the injection wells. Samples were collected by Site Geotechnical Services (SGS) and Savannah River Technology Center (SRTC) personnel. Laboratory analysis and photo-documentation were performed by SRTC. 


\subsection{Collection of Solids from Injection Wells}

During the initial stage of well development, the internal piping and instrumentation was removed from the injection well. The internal-piping consists of the injection pipe and screen which deliver the injection water to the injection well (see Figure 1). At the base of the injection screen is a sump, approximately 6 inches in length, which collects material too large to pass through the injection screen $\left(0.050^{\prime \prime}\right.$ slot). The water and material contained in this sump was collected for analysis.

Sample collection was performed by removing the sump from the injection pipe and pouring the sample into either a selfsealing plastic bag or a glass sample jar. Before pouring the sample, the sump was gently agitated by shaking to suspend the sediment. Radiological control surveyed the samples for radiation before they were released from the $\mathrm{H}$ Area Seepage Basins facility. The samples were then stored at room temperature prior to analysis.

Table I is a list of the wells that were sampled, the location of the collected material, and date of collection. Field description and photo-documentation of the material sampled is presented in Sections 4.1 and 4.2.

\begin{tabular}{|l|l|l|}
\hline \multicolumn{2}{|l|}{ Table I-Sample Descriptions } & \\
\hline WeIIID & Sampling Location & Date Sampled \\
\hline HIN-1 & Injection Pipe Sump & $3 / 16 / 98$ \\
\hline HIN-2 & Injection Pipe Sump & $3 / 26 / 98$ \\
\hline HIN-2 & Inside Screen Scraping & $3 / 26 / 98$ \\
\hline HIN-2 & Outside Screen Scraping & $3 / 26 / 98$ \\
\hline HIN-3 & Injection Pipe Sump & $3 / 20 / 98$ \\
\hline HIN-5 & Injection Pipe Sump & $3 / 23 / 98$ \\
\hline HIN-6 & Injection Pipe Sump & $3 / 20 / 98$ \\
\hline HIN-7 & Injection Pipe Sump & $3 / 24 / 98$ \\
\hline HIN-8 & Injection Pipe Sump & $3 / 30 / 98$ \\
\hline HIN-9 & Injection Pipe Sump & $3 / 18 / 98$ \\
\hline HIN-10 & Injection Pipe Sump & $3 / 18 / 98$ \\
\hline
\end{tabular}

In addition to material collected from the injection pipe sump, scrapings of gelatinous solids from the inside and outside of the screen in injection well HIN-2 were collected. Note that a sample from well HIN-4 was not collected due to miscommunication with the well development crew.

\subsection{Macroscopic Description of Solids}

Field notes were recorded when solids were collected from the H-Area injection wells. Section 4.1 summarizes the field observations.

\subsection{Photographic Documentation of Solids}

Photographic documentation of the solids recovered from injection wells was accomplished in two ways. Digital photographs were taken without magnification and via optical microscopy at a magnification between 10 and 70 times. Optical microscopy photos were taken at several spots of interest and no attempts were made to randomize this process.

\subsection{Mineralogical Characterization of Injection Well Solids}

The samples collected during well redevelopment and described above were dry-sieved through a 2-mm sieve and material passing through this sieve was collected for XRD analysis. XRD data were obtained on air-dried material deposited on glass sample holders using Vaseline as a binder. The powder XRD patterns were collected at room temperature, $22^{\circ} \mathrm{C}$, using a Siemens D500 x-ray powder diffractometer with Bragg-Bretano geometry using $\mathrm{Cu} \mathrm{K} \alpha$ radiation $(45 \mathrm{kV}, 40 \mathrm{~mA})$ with a $1^{\circ}$ divergence slit, $0.15^{\circ}$ detector slit, scintillation detector, and a diffracted beam graphite monochromator. Quartz was used as an external standard to verify instrument d-spacing calibration. Intensities were collected by step-scanning from $5^{\circ}$ to $70^{\circ}$ $(2 \Theta)$ with a step size of $0.02^{\circ}(2 \Theta)$ and a counting time of 2 seconds for each step. The goniometer was controlled by the PC package Datascan supplied by MDI, Inc. Qualitative analysis of the various phases and other data processing were performed using the computer program Jade ${ }^{\oplus}$ from MDI, Inc.

\subsection{Injection Tank Water and Solids Characterization}

Characterization of treated water and associated suspended solids was conducted on a single grab sample collected from the injection tanks at both the F- and $\mathrm{H}$ Area water treatment units. Characterization was intended to evaluate the injection tank waters as a possible source of solids observed in the system injection wells. A single grab sample was collected from the injection tank at both the F- and H-Area WTUs on 12/15/97. Two samples from each area were collected without preservation in 2-L polyethylene bottles. One 2-L sample was filtered through a disposable 0.20 micron filter. Filtrate from 
his sample and the unfiltered sample were analyzed for major cations using ion coupled emission spectroscopy, major anions via ion chromatography, total inorganic and organic carbon, and $\mathrm{pH}$. All analyses were completed by the Analytical Development Section of SRTC and samples for major cation analyses were acidified to approximately $0.1 \mathrm{M} \mathrm{HNO}_{3}$ with concentrated spectrophotometric grade acid prior to analysis.

The solids collected on the 0.2-micron filter, after air-drying, were analyzed by XRD without further preparation with the methods described in Section 3.3.

\subsection{Results and Conclusions}

This section discusses the analytical results, including photo-documentation and mineralogical characterization of injection well solids and characterization of the injection tank water. Details of the analysis are provided below. Photographs and XRD diffraction patterns are presented as attachments to this report.

\subsection{Macroscopic Description of Solids}

Overall, all injection wells sampled contained some material in the injection pipe sump. This material consisted of a mixture of large solids, gelatinous material, very fine-grained particulates, and water. The larger material consisted mainly of fiberglass fibers, coarse sand, and PVC pipe, both shavings and larger fragments (some as large as 1-inch across). The gelatinous material was pale gray-green in color and was observed coating the inside and outside of the injection piping. This material was also observed in the discharge water pumped from the well during redevelopment. The fine-grained material formed an orange-tan colored "collodial" suspension when agitated, but settled out over time. This material was too small to identify macroscopically.

\subsection{Photographic Documentation of Solids}

The samples collected from the $\mathrm{H}$ Area injection wells were dry sieved using a 2-mm sieve and the retained material was then air dried and collected in a petri dish. Photographs of the solids are presented in Appendix A. The macroscopic photographs were taken with a digital camera and are unmagnified. For reference, the diameter of the petri dish containing the samples is approximately 2 inches. The magnified images were taken using magnification between 10 and 70 times. Table II summarizes the material collected from each well.

\begin{tabular}{|l|l|l|}
\hline \multicolumn{3}{|c|}{ Table II-Summary of Photo-documentation for H Area Injection Well Solids } \\
\hline WeIIID & Photograph & Description of Major Constituients Identified \\
\hline HIN-1 & No Magnification & Large PVC fragments and shavings, fiberglass, medium-grained sand \\
\hline HIN-1 & Magnified 10-70X & PVC and other plastic, sand \\
\hline HIN-2 & No Magnification & PVC fragments, fiberglass, gray gelatinous material, medium-grained sand \\
\hline HIN-3 & No Magnification & PVC and other plastic, fiberglass, gray gelatinous material, sand \\
\hline HIN-3 & Magnified 10-70X & Thin PVC strip, plastic hook, fiberglass, sand \\
\hline HIN-5 & No Magnification & PVC and other plastic, fiberglass \\
\hline HIN-6 & No Magnification & PVC strips, abundant fiberglass in gray gelatinous material matrix \\
\hline HIN-6 & Magnified 10-70X & Pale gray gelatinous material \\
\hline HIN-7 & No Magnification & Large PVC fragments, fiberglass, gelatinous material, fine-grained sand \\
\hline HIN-7 & Magnified 10-70X & PVC fragment, some fiberglass \\
\hline HIN-8 & No Magnification & PVC and metal fragments, fiberglass, other plastic, fine-grained sand \\
\hline HIN-9 & No Magnification & Thin PVC strips, plastic, gray gelatinous material, sand \\
\hline HIN-9 & Magnified l0-70X & Plastic strip \\
\hline HIN-9 & No Magnification & Fine grained sand in mud matrix \\
\hline HIN-10 & No Magnification & PVC shavings, abundant fiberglass, medium-grained sand \\
\hline
\end{tabular}

\subsection{Mineralogical Characterization of $\mathbf{H}$ Area Injection Well Solids}

XRD diffraction patterns from the less than 2-mm fraction are attached as Appendix B. Table III is a summary of the major mineral phases identified in these samples.

The diffraction patterns exhibited two general patterns. In about one-half of the samples analyzed, there was a broad large peak centered at a $2 \Theta$ of about 22 degrees. The broadness of this peak is indicative of an amorphous material such as $\mathrm{SiO}_{2}{ }^{*} \mathrm{nH}_{2} \mathrm{O}, \mathrm{Al}(\mathrm{OH})_{x}$, and $\mathrm{Fe}(\mathrm{OH})_{x}$. The d-spacing, however, is most consistent with an amorphous silica-phase like cristobalite. In all the diffraction patterns, a variety of crystalline mineral phases were identified. These include clay/micaceous minerals (kaolinite, muscovite, and montmorillonite), metal oxy-hydoxides (gibbsite, bayerite, lepidocrocite, goethite), quartz, zeolite (clinoptilolite and heulandite). Of the minerals identified during these experiments it is thought that the montmorillonite (from the bentonite chemistry), zeolite (from the polishing columns), and metal oxyhydroxides/amorphous material (from the neutralization process) could have been added directly to the wells from the 
WTU. However, metal oxy-hydroxides, amorphous material, kaolinite, muscovite, and quartz are all commonly found in SRS aquifer material. Therefore, with the existing data, a definitive source determination for these materials cannot be made. Because XRD analysis was made only to identify mineral phases present in the injection wells, little can be said about the relative mass contribution of these material to the total recovered solids. Finally, any future mineralogy studies should include aquifer material blanks from areas unimpacted by the injection process as well as elemental composition data on the recovered solids.

\begin{tabular}{|c|c|c|}
\hline \multicolumn{3}{|c|}{ 3. Table III-Summary of X-Ray Diffraction Data for $H$ Area Injection Well Solids } \\
\hline WellID & Sampling Location & Major Mineral Phases Identified \\
\hline HIN-1 & Injection Pipe Sump & Kaolinite, Muscovite, Lepidocrocite, Montmorillonite, Gibbsite \\
\hline HIN-2 & Tnjection Pipe Sump & Kaolinite, Muscovite, Quartz \\
\hline HIN-2 & Inside Screen Scraping & Amorphous ( $\mathrm{SiO}_{2}$ ?), Quartz, Kaolinite, Muscovite, Rutile, Rieheckite \\
\hline HIN-2 & Outside Screen Scraping & Amorphous ( $\mathrm{SiO}_{2}$ ?), Quartz, Kaolinite, Muscovite \\
\hline HIN-3 & Injection Pipe Sump & Amorphous $\left(\mathrm{SiO}_{2}\right.$ ?), Kaolinite, Muscovite, Montmorillonite, Heulandite \\
\hline HIN-5 & Tnjection Pipe Sump & Amorphous $\left(\mathrm{SiO}_{2}\right.$ ?), Kaolinite, Muscovite, Quartz, Montmorillonite \\
\hline HIN-6 & Injection Pipe Sump & Amorphous $\left(\mathrm{SiO}_{2}\right.$ ?), Kaolinite, Montmorillonite, Clinoptilolite, Quartz \\
\hline HIN-7 & Tnjection Pipe Sump & $\begin{array}{l}\text { Amorphous ( } \mathrm{SiO}_{2} \text { ?), Muscovite, Kaolinite, Montmorillonite, Quartz, Rutile, } \\
\text { Albite, Bayerite }\end{array}$ \\
\hline HIN-8 & Tnjection Pipe Sump & $\begin{array}{l}\text { Muscovite, Lepidocrocite, Kaolinite, Montmorillonite, Quartz, Albite, } \\
\text { Goethite }\end{array}$ \\
\hline HIN-9 & Injection Pipe Sump & Muscovite, Lepidocrocite, Kaolinite, Quartz \\
\hline HIN-10 & Injection Pipe Sump & Kaolinite, Muscovite, Quartz \\
\hline
\end{tabular}

\subsection{Injection Tank Water and Solids Characterization}

The results of the analysis of both filtered and unfiltered water from the injection tanks in both F- and $\mathrm{H}$ Areas are presented in Table IV and XRD diffraction patterns are presented in Appendix C. Given that WTU influent water organic carbon content is on the order of several $\mathrm{mg} \mathrm{C} / \mathrm{L}$, the most surprising finding is the very high organic carbon contents in both injection tank samples. These data are strongly suggestive of microbial activity and high microbial activity is thought to pose a significant injection well clogging potential. The filtration process removed between 30 and 80 percent of the organic carbon and 75 percent of the aluminum in the F-Area sample. The removal during this filtration step indicates there is a significant suspended solids and/or colloidal component to the organic matter and aluminum in these systems that could contribute to injection well clogging.

The bid specification indicates that sulfate injection to the wells should be avoided. This, however, does not appear to be occurring as the sulfate concentrations in the injection tank for both areas is elevated over WTU influent concentrations. This is likely due to the use of sulfuric acid as a means of final $\mathrm{pH}$ adjustment.

\begin{tabular}{|l|l|l|l|l|}
\hline 3. Table IV - Results of Tnjection Tank Water Analyses \\
\hline \multirow{2}{*}{ Sample Location } & H-Area Injection Tank & \multicolumn{2}{l|}{ F-Area Injection Tank } \\
\cline { 2 - 5 } & Unfiltered & Filtered & Unfiltered & Filtered \\
\hline & & & & \\
\hline pH(std units) & 7.2 & 7.3 & 5.8 & 5.7 \\
\hline Inorganic Carbon (mg C/L) & 7.6 & 6.7 & 0.2 & 0.3 \\
\hline Organic Carbon (mg C/L) & 58.2 & 11.6 & 25.0 & 16.9 \\
\hline & & & & \\
\hline Anions & & & & \\
\hline Nitrate (mg/L) & 78 & 75 & 491 & 491 \\
\hline Sulfate (mg/L) & 48 & 48 & 26 & 26 \\
\hline & & & & \\
\hline Cations & & & & \\
\hline Aluminum (mg/L) & $<0.216$ & $<0.216$ & 1.80 & 0.43 \\
\hline Calcium (mg/L) & 8.41 & 8.28 & 54.06 & 54.36 \\
\hline Sodium (mg/L) & 57.71 & 57.27 & 171.02 & 171.35 \\
\hline ron (mg/L) & $<0.017$ & $<0.017$ & $<0.017$ & $<0.017$ \\
\hline Silica (mg/L) & 2.77 & 2.85 & 3.92 & 3.96 \\
\hline
\end{tabular}

Four separate samples, two from solids isolated from each of the WTU injection tanks, were analyzed by XRD analysis and the diffraction patterns are included in Appendix II. Similar to about one-half of the samples collected from the injection wells, a very broad and large peak dominates XRD patterns from these samples and is centered at a $2 \Theta$ of about 22 degrees. Additionally, the following crystalline mineral phases were identified: for $\mathrm{H}$ Area - muscovite, montmorillonite, and beidelite (a 2:1 clay similar to montmorillonite); and for the $\mathrm{F}$ Area - muscovite and gypsum (CaSO $\mathrm{C}_{4}$. Both muscovite and 
montmorillonite were observed in samples collected from the H-Area injection wells. The presence of these minerals in the injection tank is consistent with WTU as a source, at least in part, of these minerals in the H-Area injection wells. Injection and/or precipitation of gypsum in the aquifer could produce significant aquifer clogging. Under the conditions of high calcium and sulfate concentrations the precipitation is unavoidable. Therefore, efforts should be made to reduce the addition of calcium and sulfate to avoid or minimize this problem.

\subsection{Recommendations}

This study indicates that performance degradation in the injection wells could be due to both chemical and biological fouling of the injection well and surrounding aquifer. This conclusion is based on the limited data presented above. Generally, it is thought that additional biogeochemical parameters should be collected on water being injected from the WTUs. This should include routine analysis (on at least a weekly basis) of $\mathrm{pH}$, redox potential, total organic carbon, biological oxygen demand, chemical oxygen demand, turbidity, total suspended solid and on a less frequent basis (about monthly) major ion chemistry and microbial counts. Furthermore, it is recommended that cone penetrometer collection of aquifer material and associated porewater near the injection wells be initiated for a more complete study of these processes. In addition to the techniques used in this study, intact core should be collected for permeability testing as a function of distance from injection point (a background unimpacted control sample would be essential for such a study). A mechanistic understanding of this process is necessary if there is any hope of preventing this well degradation problem in the future.

In the short term, the following actions should be taken to evaluate and minimize biological and chemical fouling of the injection wells.

It is thought from analysis of the existing data that the most credible explanation for the observed degradation of the injection well performance is biological fouling. Specifically, the following is suggested to verify, and if present, remedy this problem:

1. Analysis of both WTU influent and effluent for biological oxygen demand, chemical oxygen demand, total organic carbon, and total microbe count.

2. If results from Item 1 are positive:

A. Culture microbes to define type;

B. Develop biocide treatment (type, frequency, and dose); and

C. Activated carbon bed is expected to be a source of microbiological activity and its removal from the system should be evaluated.

Currently, sulfate and bisulfite are being added to the WTU and eventually make their way to the injection wells. High sulfate and calcium concentrations are expected to lead to the precipitation of the insoluble mineral gypsum. Furthermore, this sulfur source could act as a nutrient source and stimulate microbiological growth. It is recommended that alternatives to these sulfur sources be identified (e.g., nitric acid for sulfuric acid as the final pH adjustment agent) and implemented.

\subsection{Acknowledgements}

The authors would like to acknowledge Art Jurgenson, Dave Missmer, and Mike Summers of the ADS of STRC for their help in XRD and SEM data analysis.

\subsection{Distribution}

To: Bruce Schappell, 730-2B w/o Attachments

James Lovekamp, 730-2B

Don Toddings, 730-2B

Cc: B. Tom Butcher, 773-43A w/o Attachments

W. Ed Stevens, 773A w/o Attachments

Scott H. Reboul, 730-2B

Al Siddall, 730-2B

Joeseph Kanzleiter, 730-2B

Sean R. Bohrer, 730-2B

John Adams, 730-2B

Kevin Brewer, 730-2B

Matt Maryak, 730-2B w/o Attachments

Art Jurgenson, 773A

Dave Missmer, 773A

Mike Summers, 773A

Garrett Day, 730-2B 


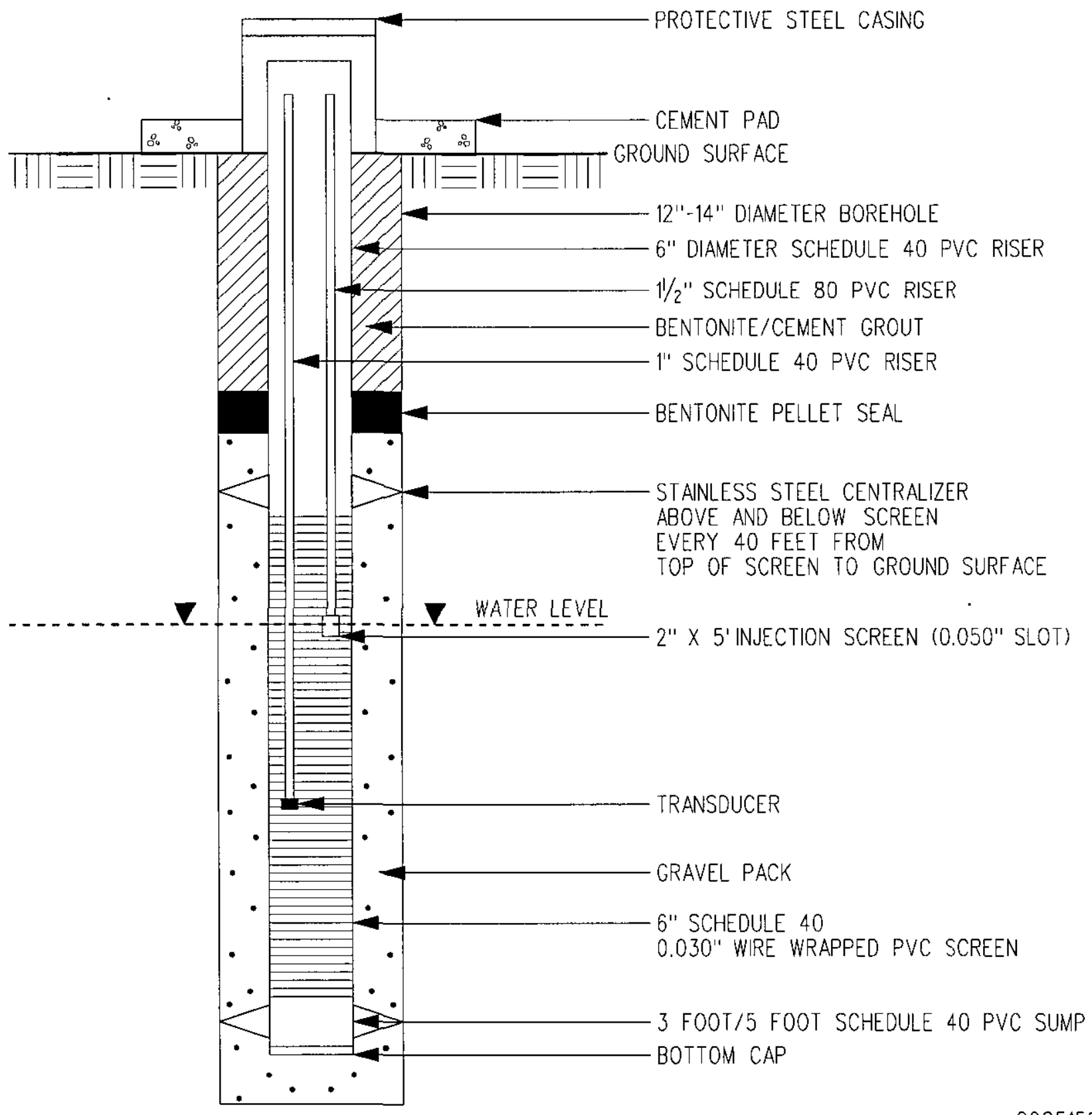

Figure 1 Generalized schematic of injection well showing location of injection pipe, screen, and sump. The sump is located at the base of the injection pipe screen. 


\section{APPENDIX A}

Photographs of Solids Collected from H Area Seepage Basins

Groundwater Remediation System Injection Wells

March 1998 
(s)

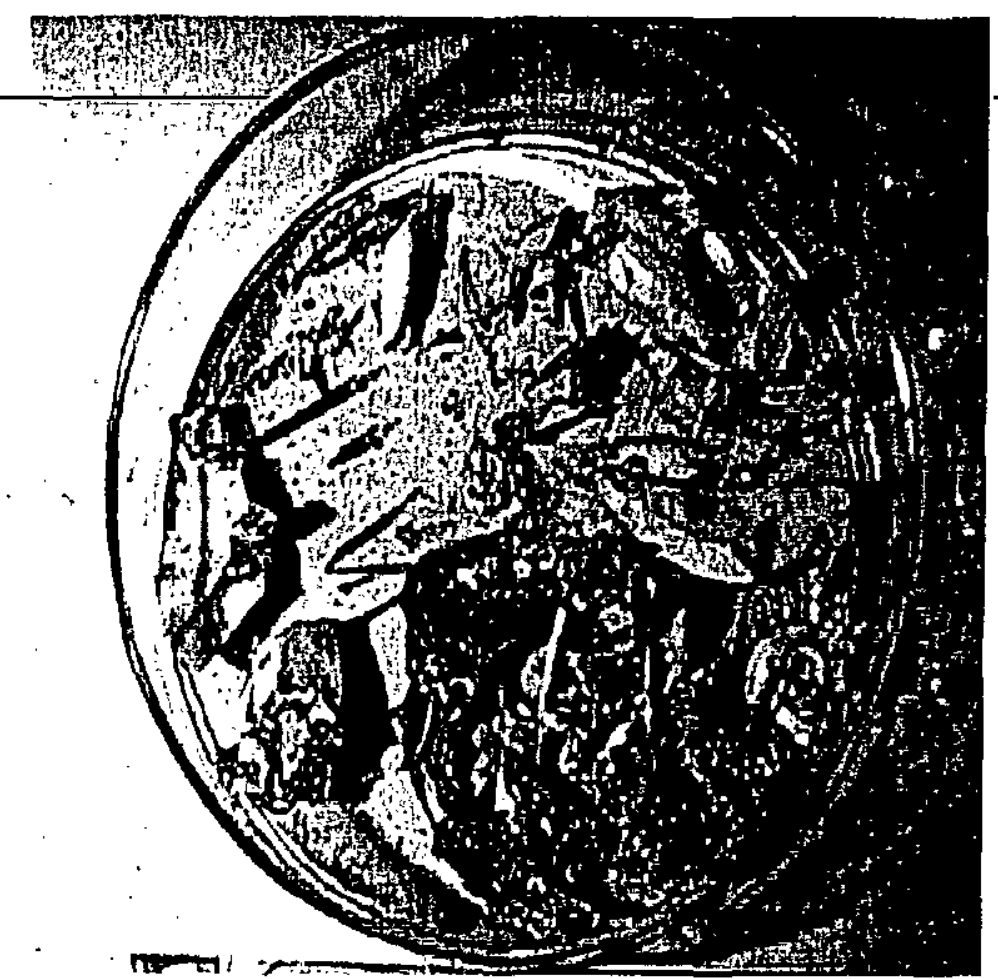

HIN-1 Solids collected from injection pipe sump.

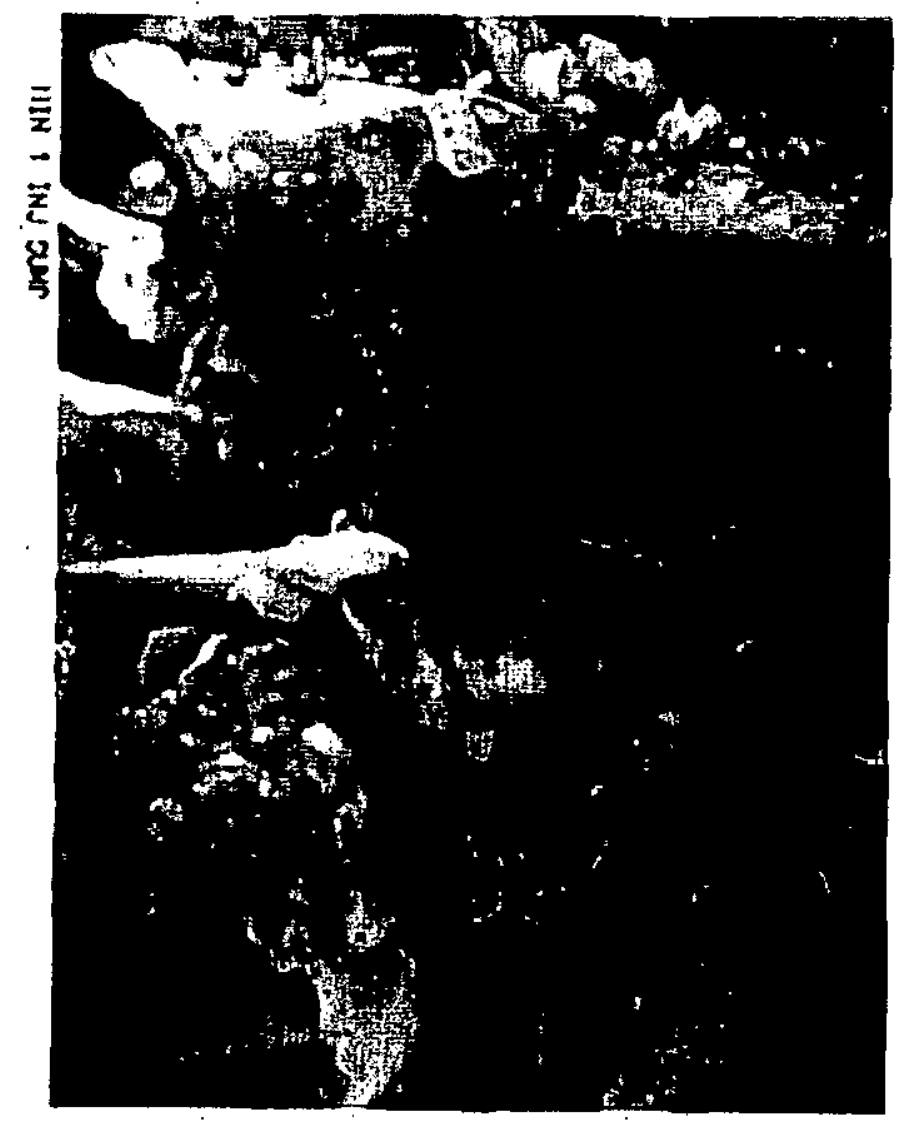

HIN-1 Magnified image of solids from injection pipe sump. 


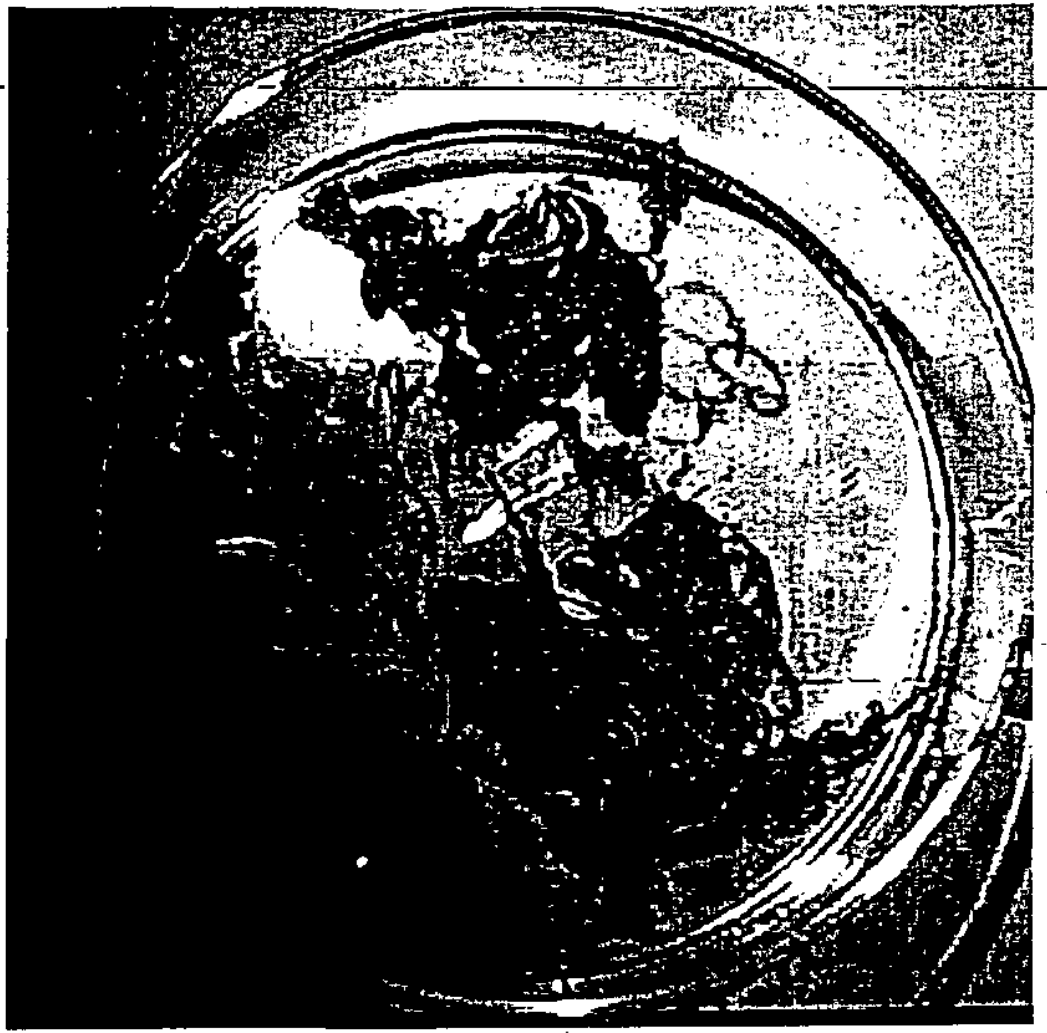

HIN-2 Solids collected from injection pipe sump.

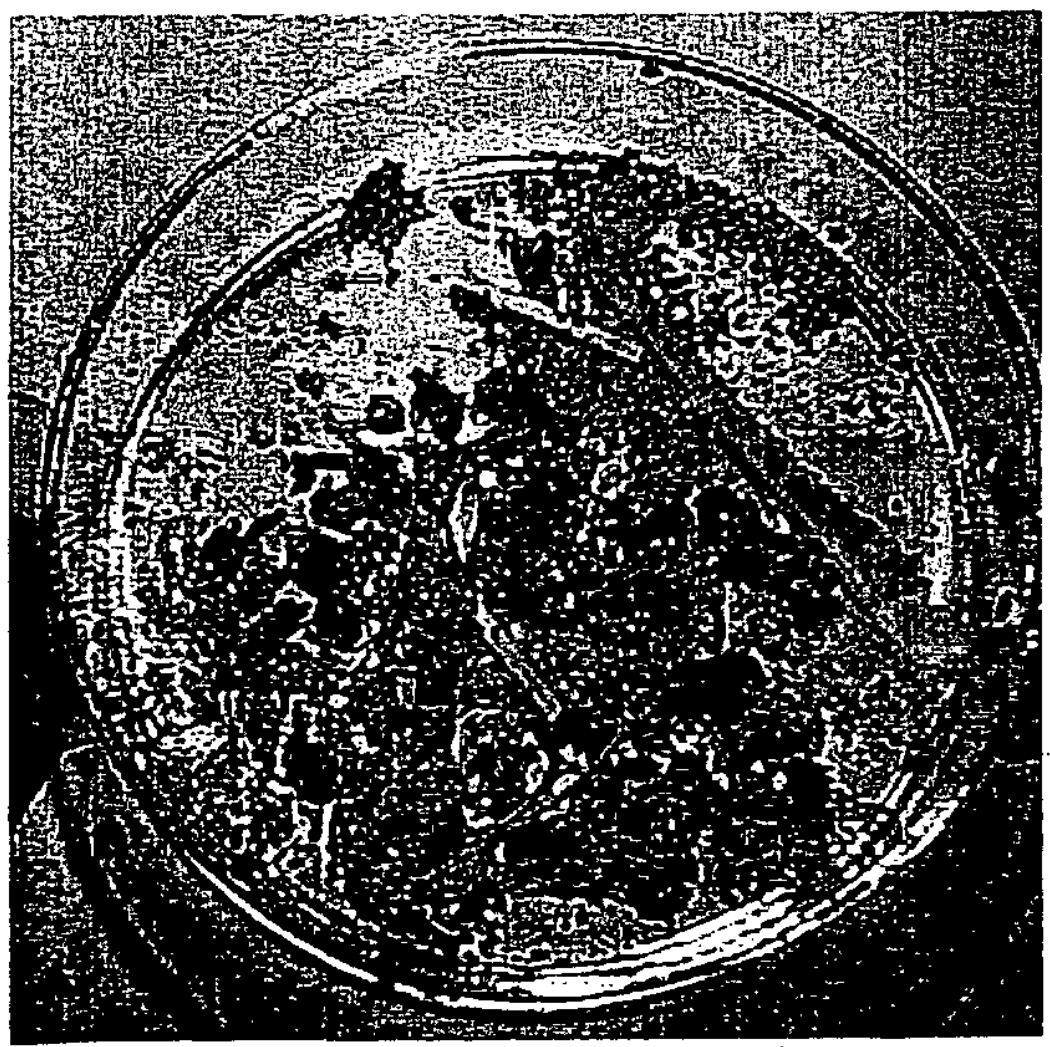

HIN-3 Solids collected from injection pipe sump. 


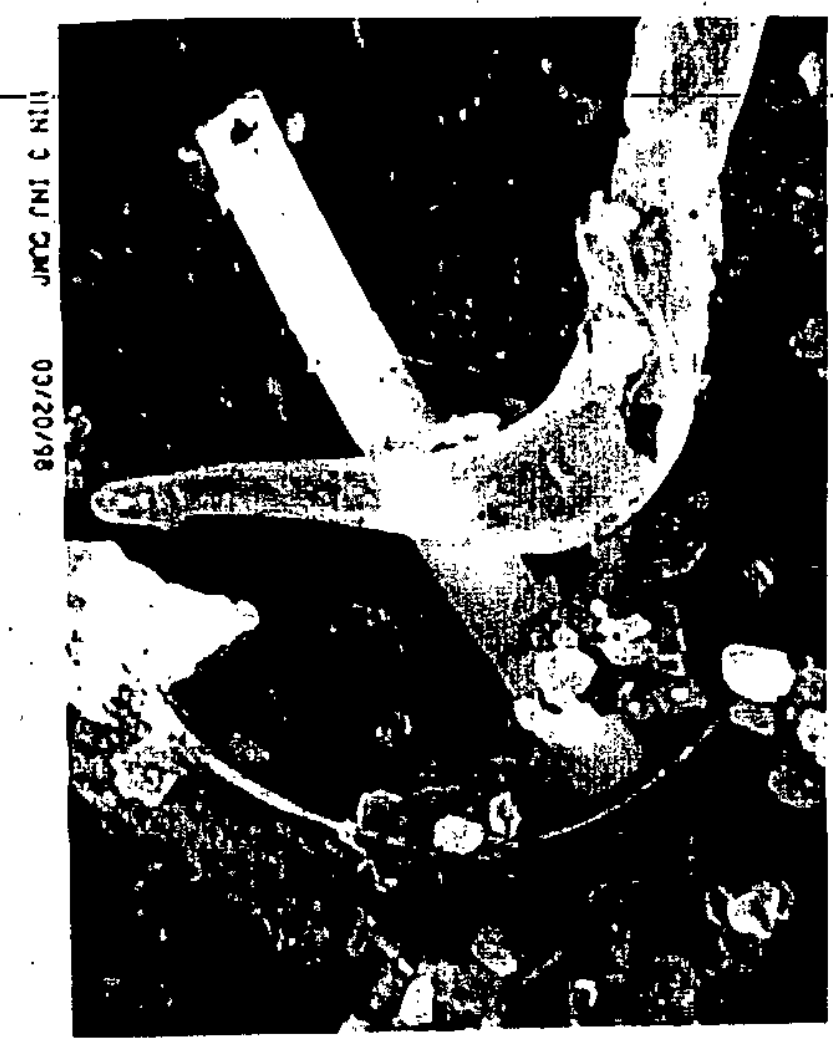

HIN-3 Magnified image of solids from injection pipe sump.

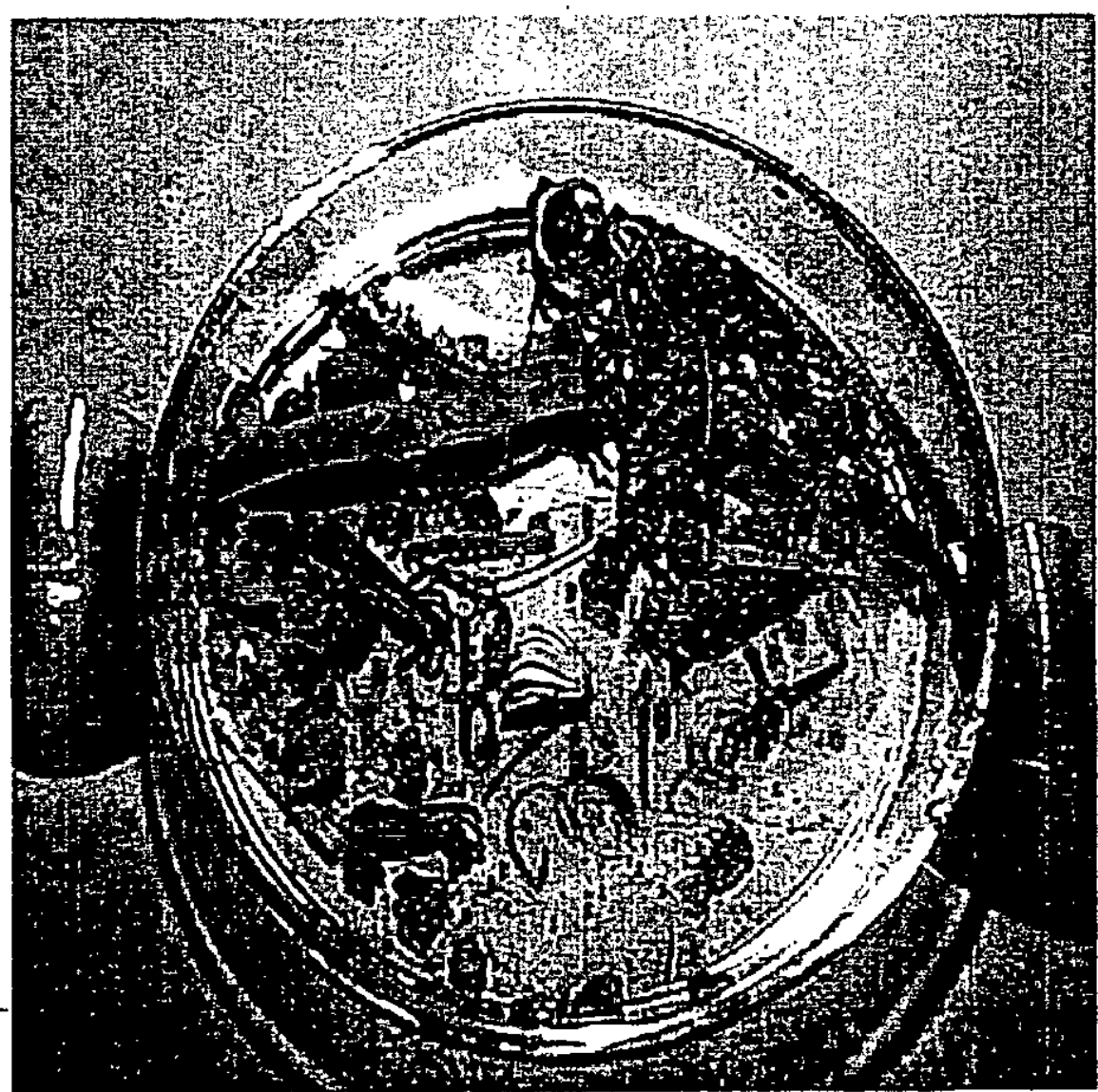

HIN-5 Solids collected from injection pipe sump. 


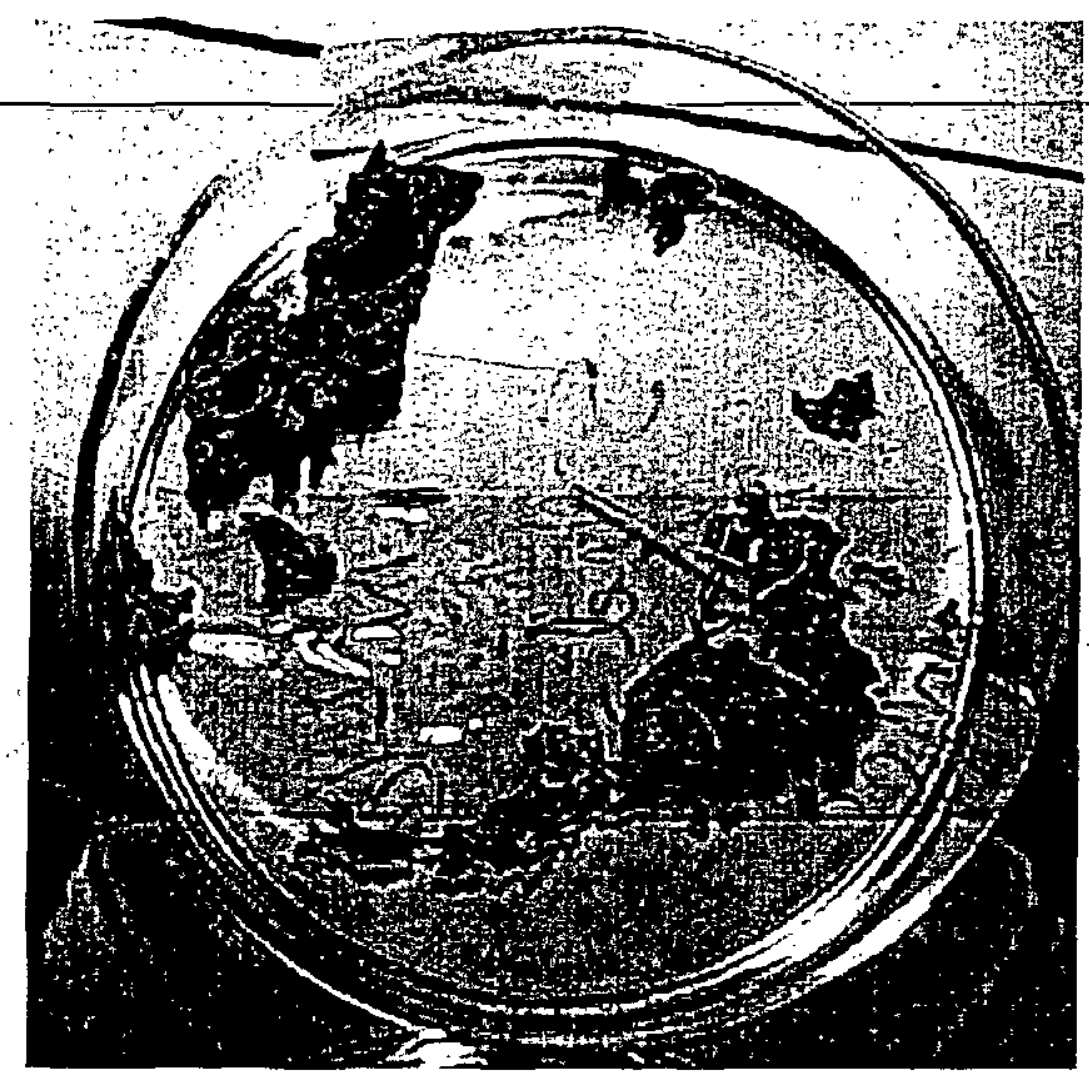

HIN-6 Solids collected from injection pipe sump.

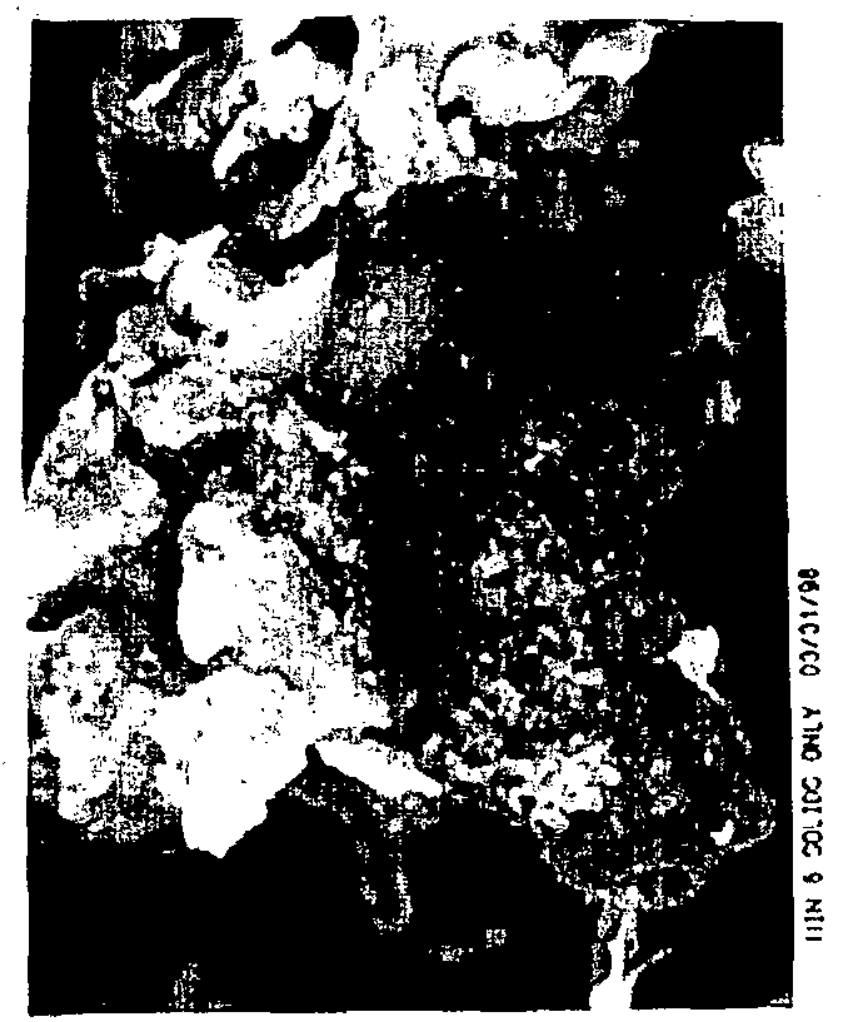

HIN-6 Magnified image of solids from injection pipe sump. 


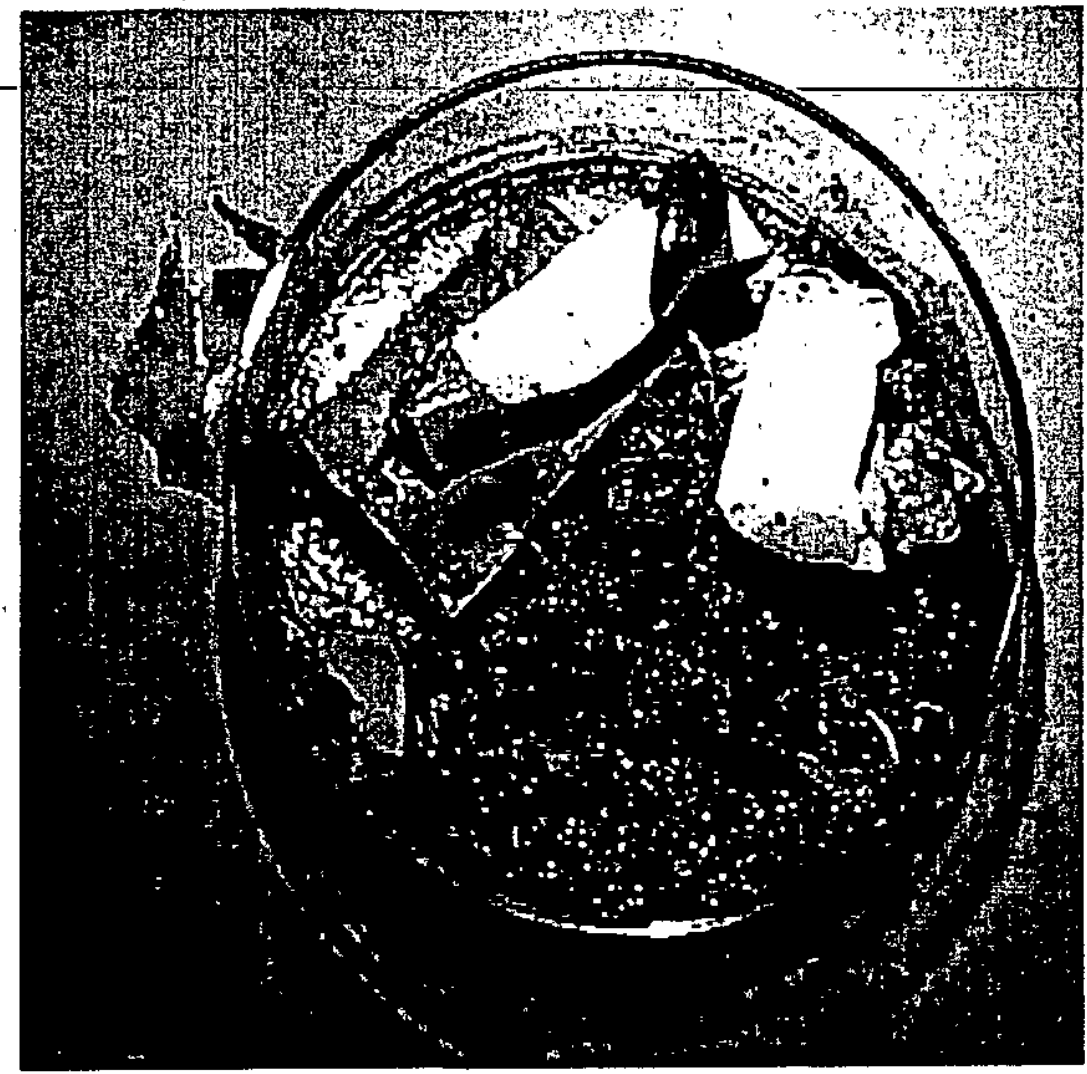

HIN-7 Solids collected from injection pipe sump.

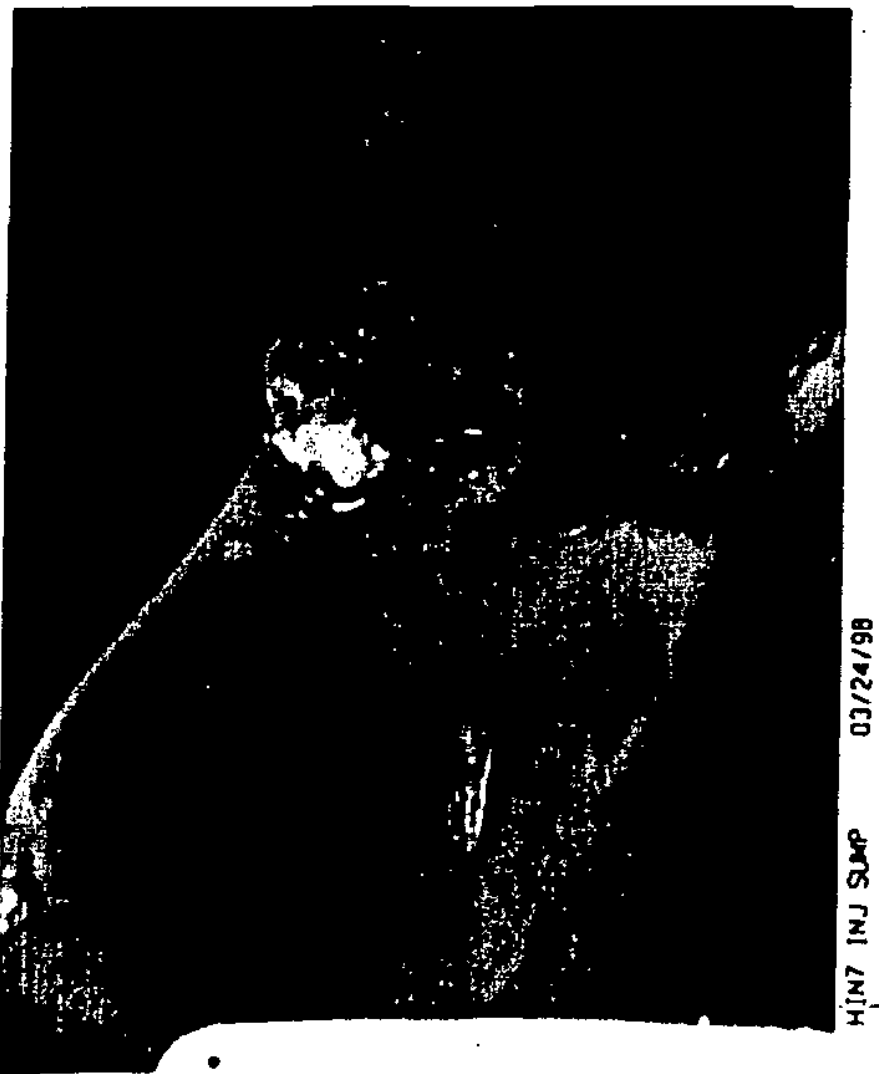

HIN-7 Magnified image of solids from injection pipe sump. 



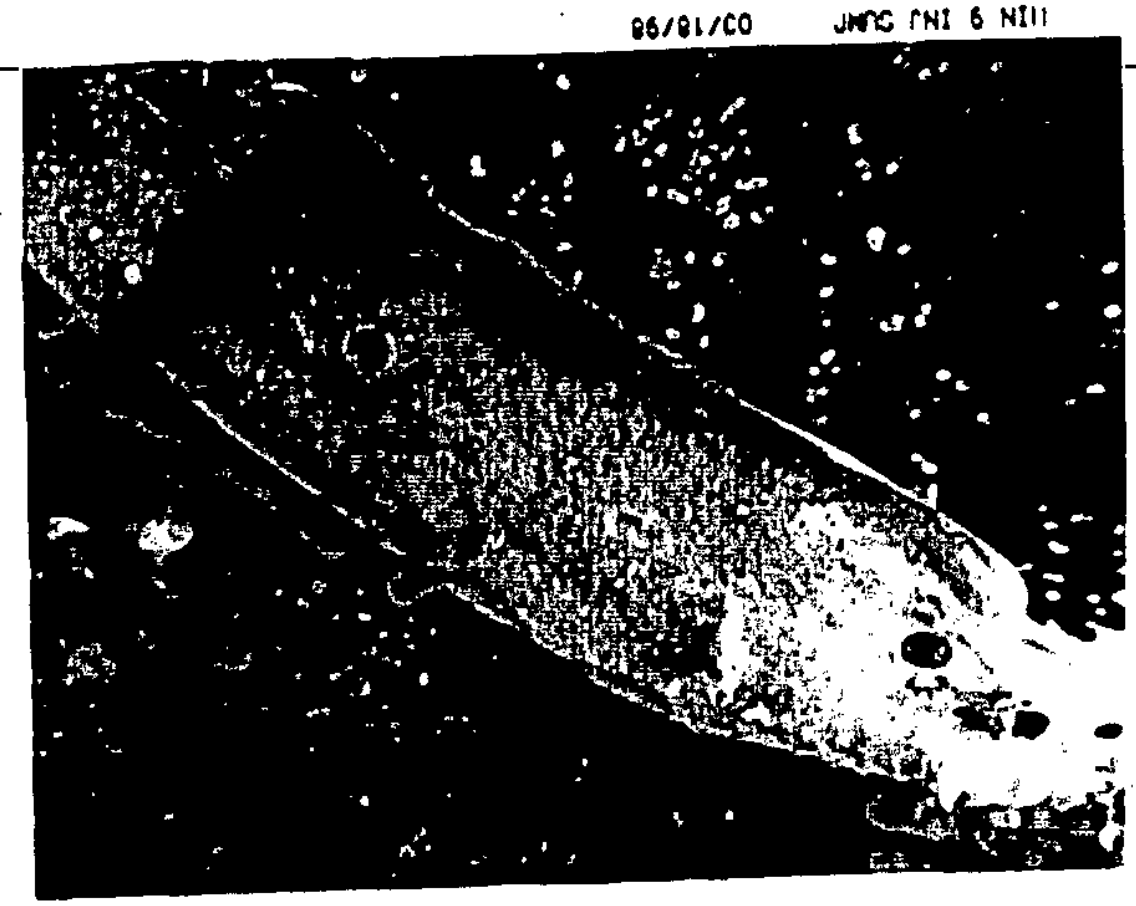

HIN-9 Magnified image of solids from injection pipe sump.

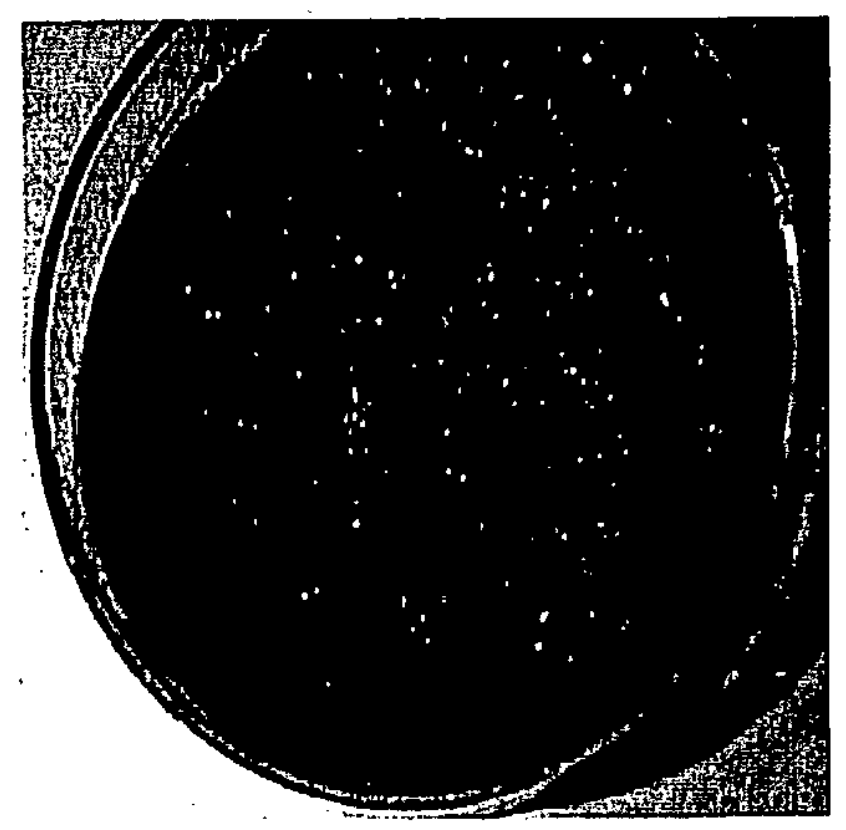

HIN-9 Fine-grained solids collected from injection pipe sump. 


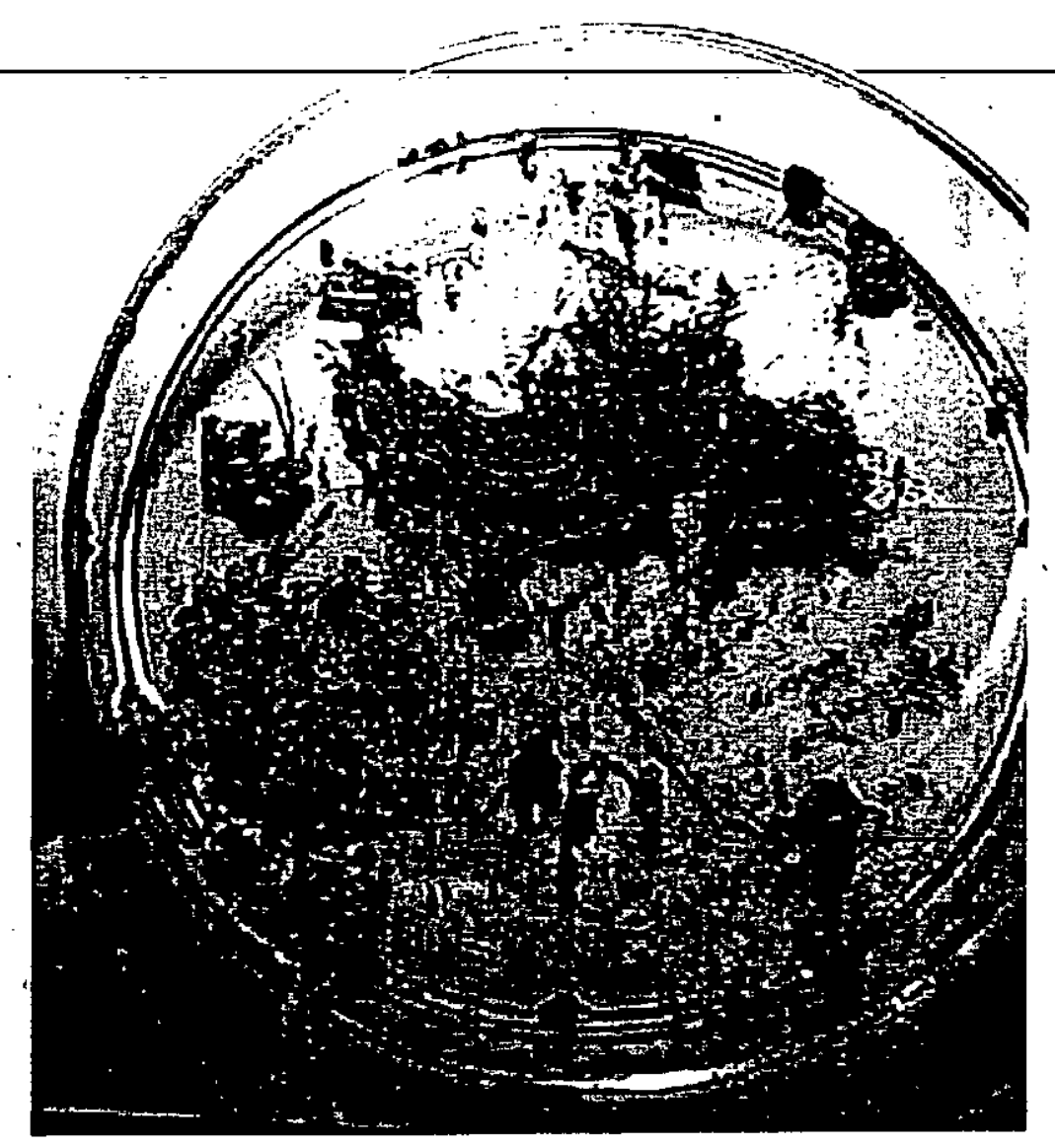

HIN-10 Solids collected from injection pipe sump. 


\section{APPENDIX B}

XRD Diffraction Patterns of Solids Collected from $H$ Area Seepage Basins

Groundwater Remediation System Injection Wells

March 1998 

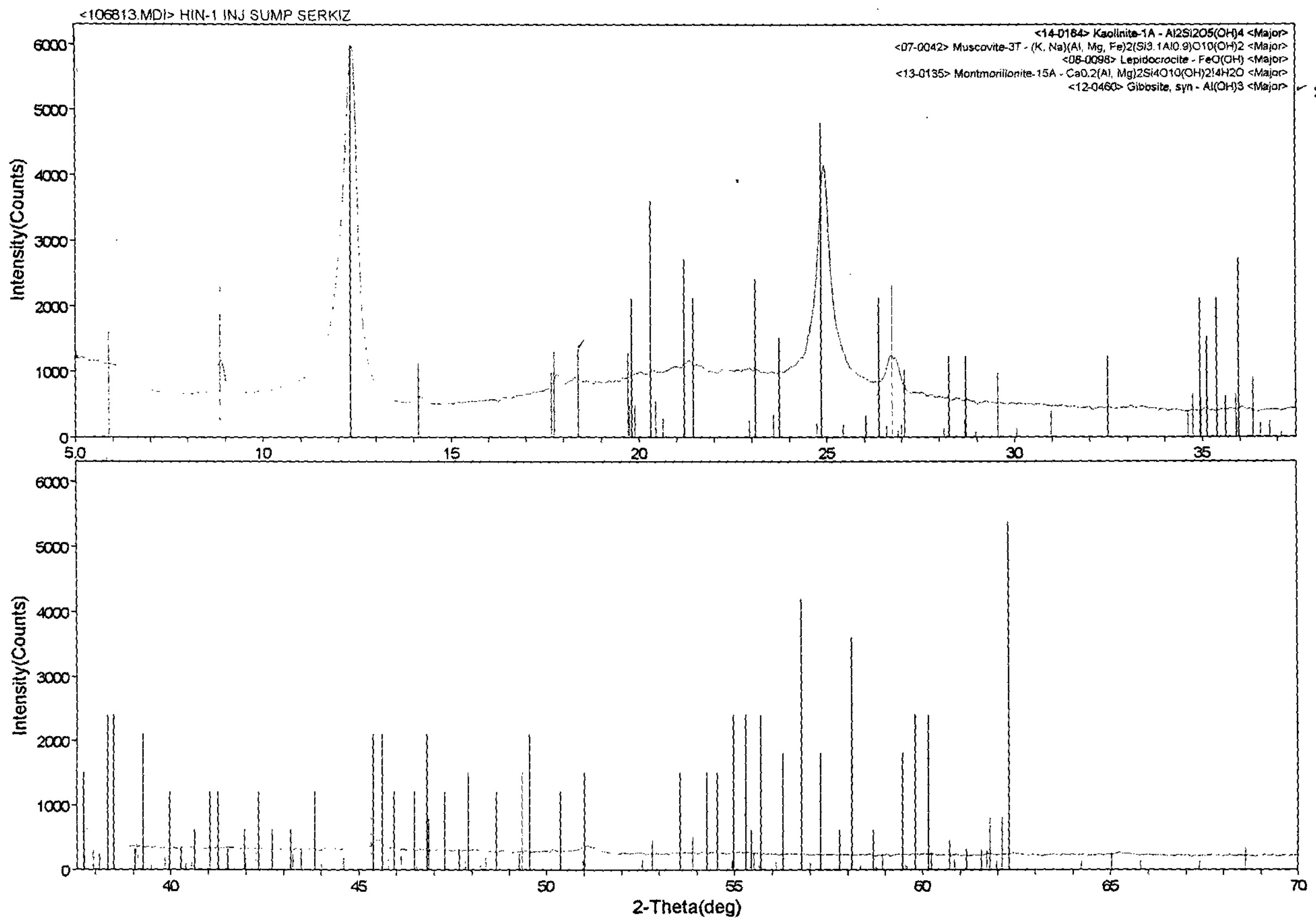

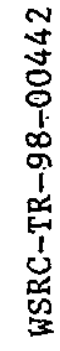



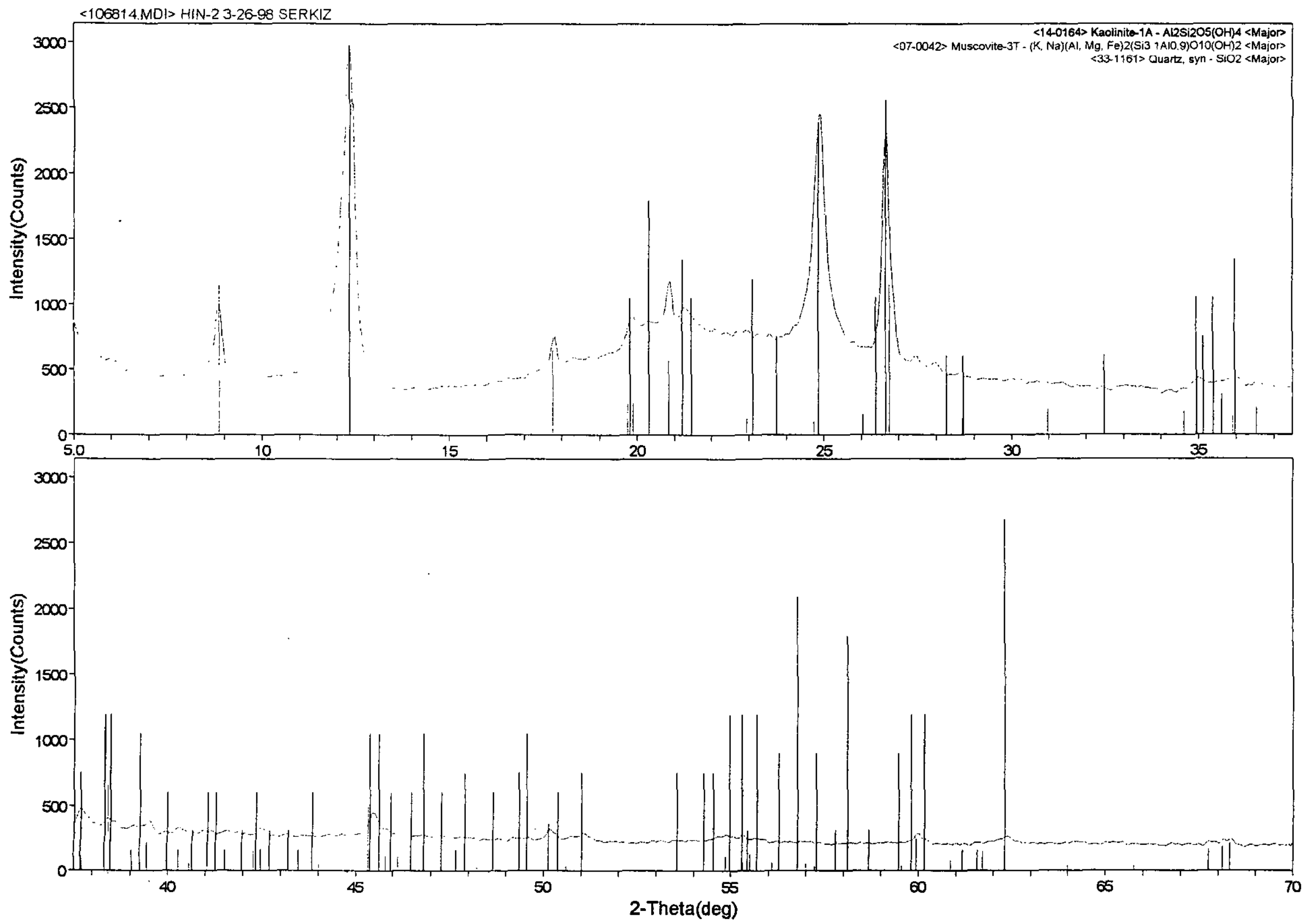

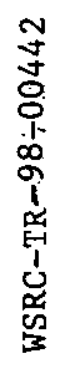


1 rumaruy umorphous-Noth sample

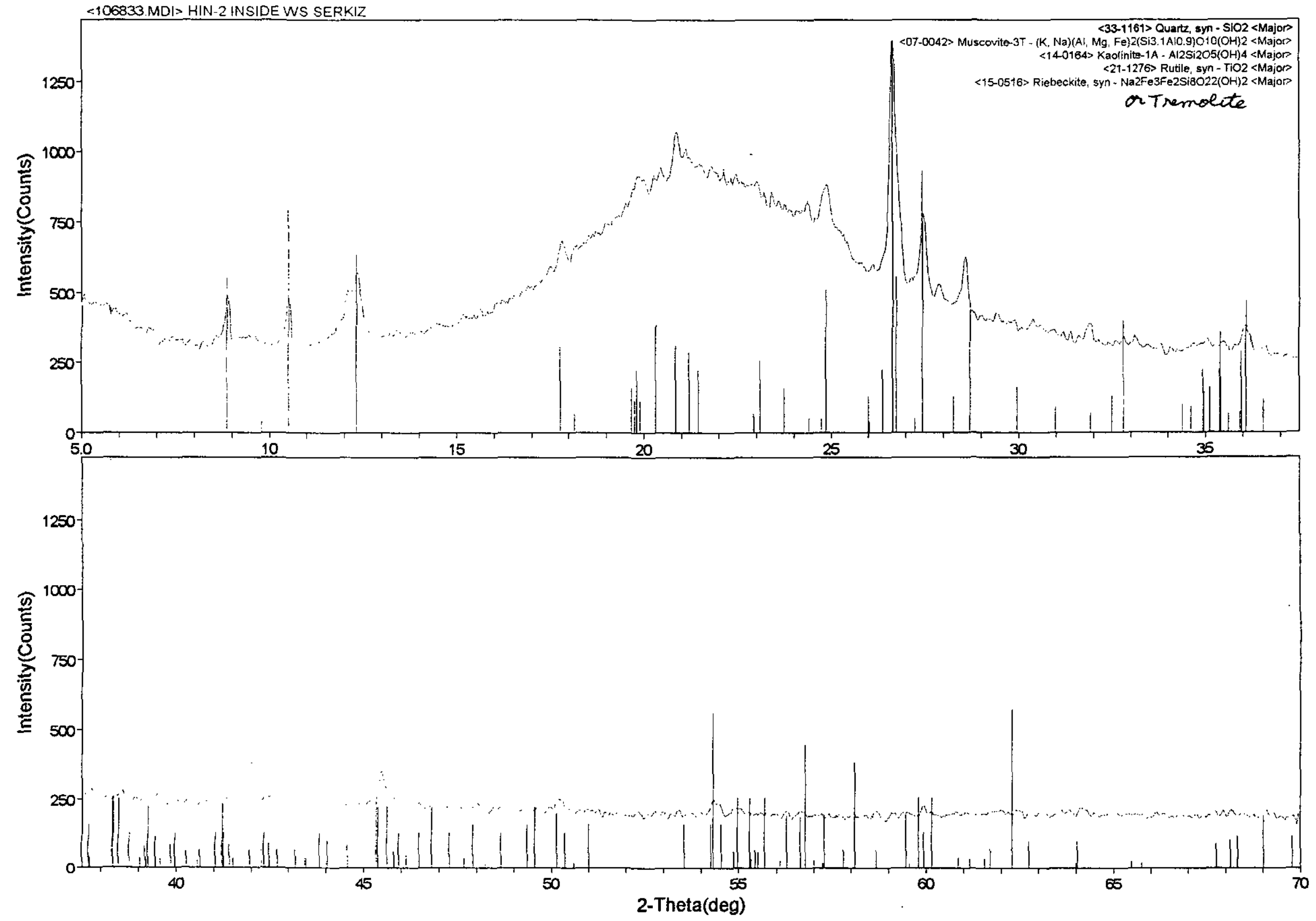


nan. $1-\cdots \cdots=$
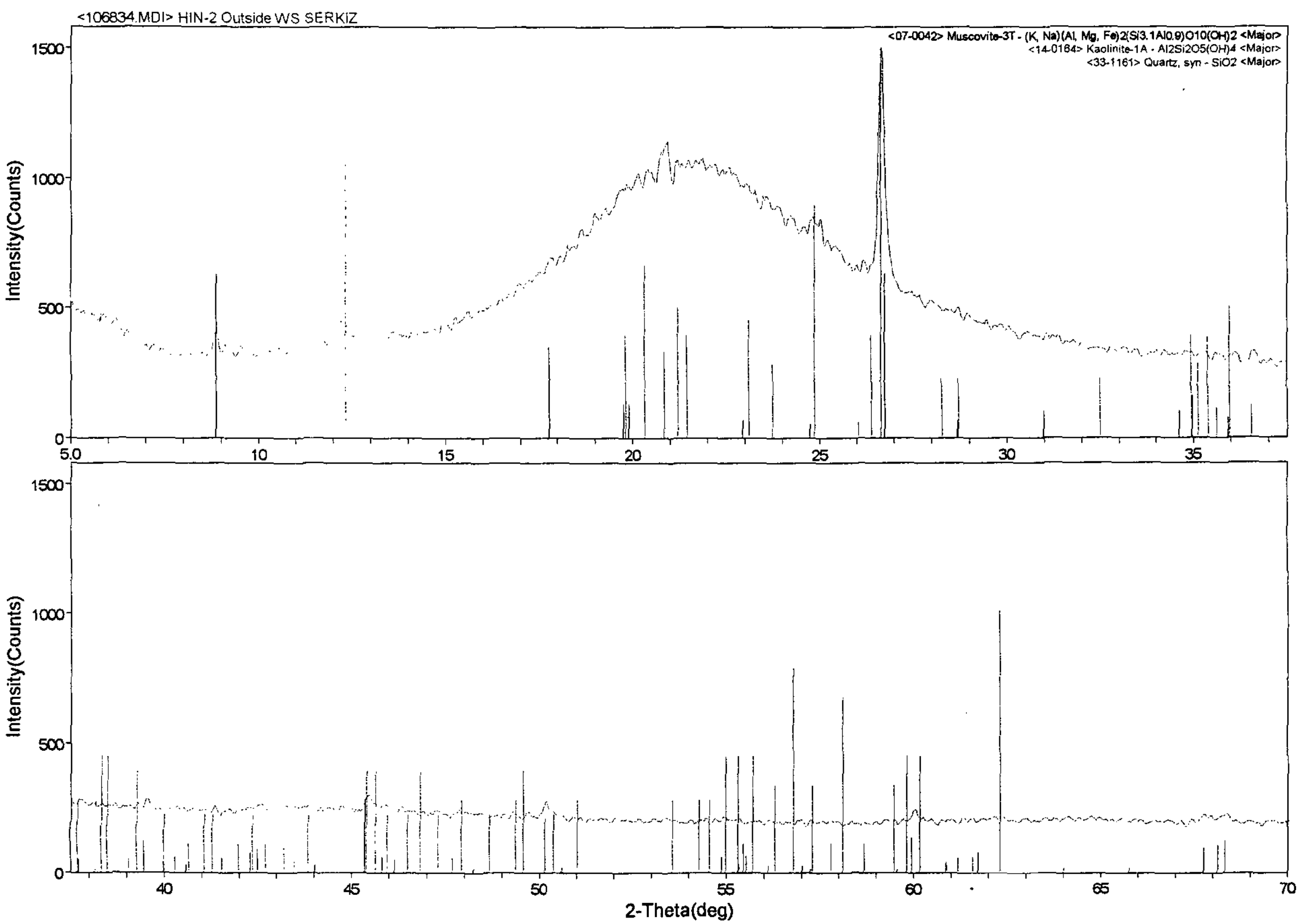

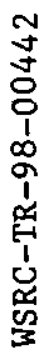



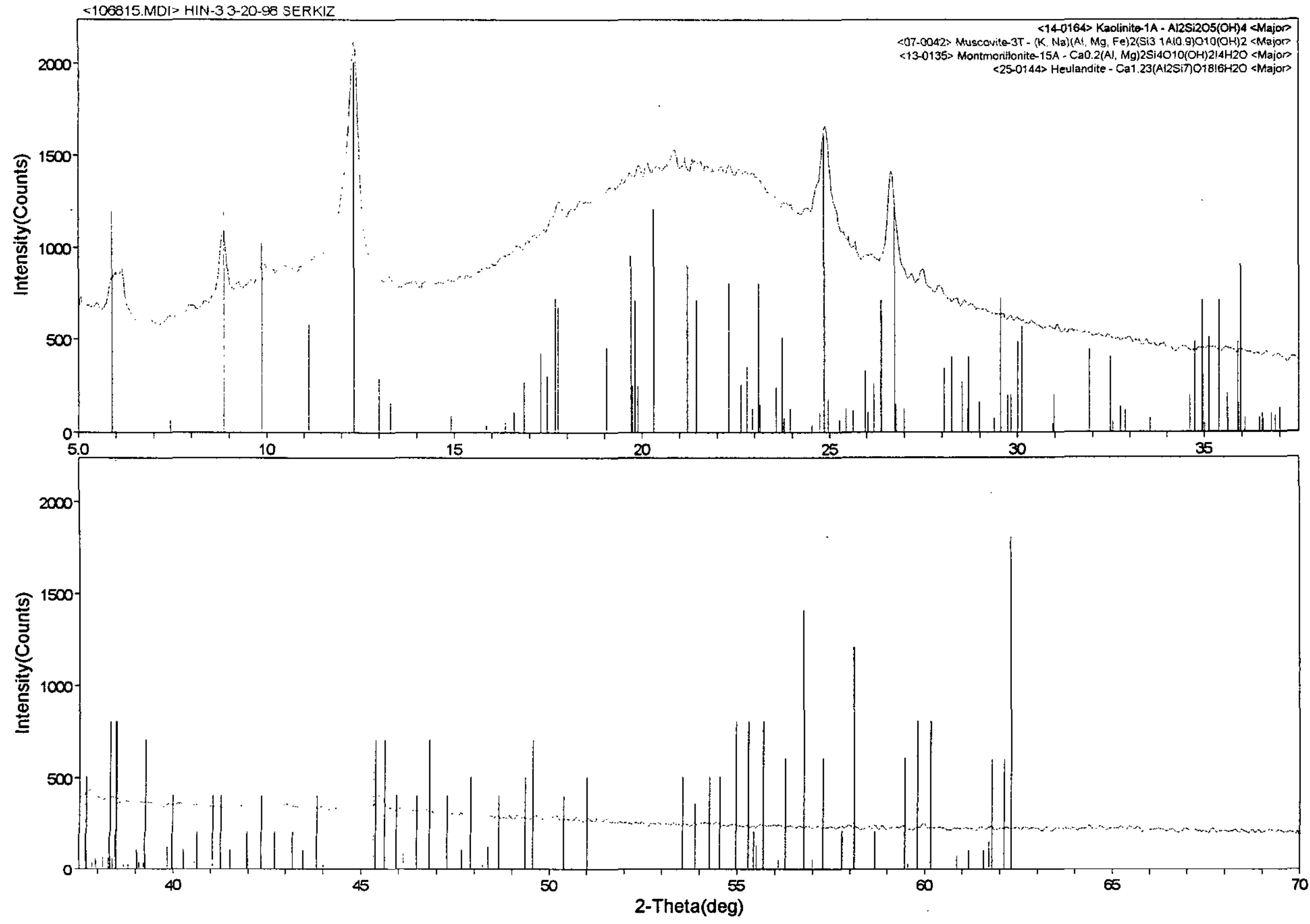

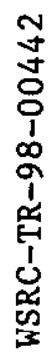



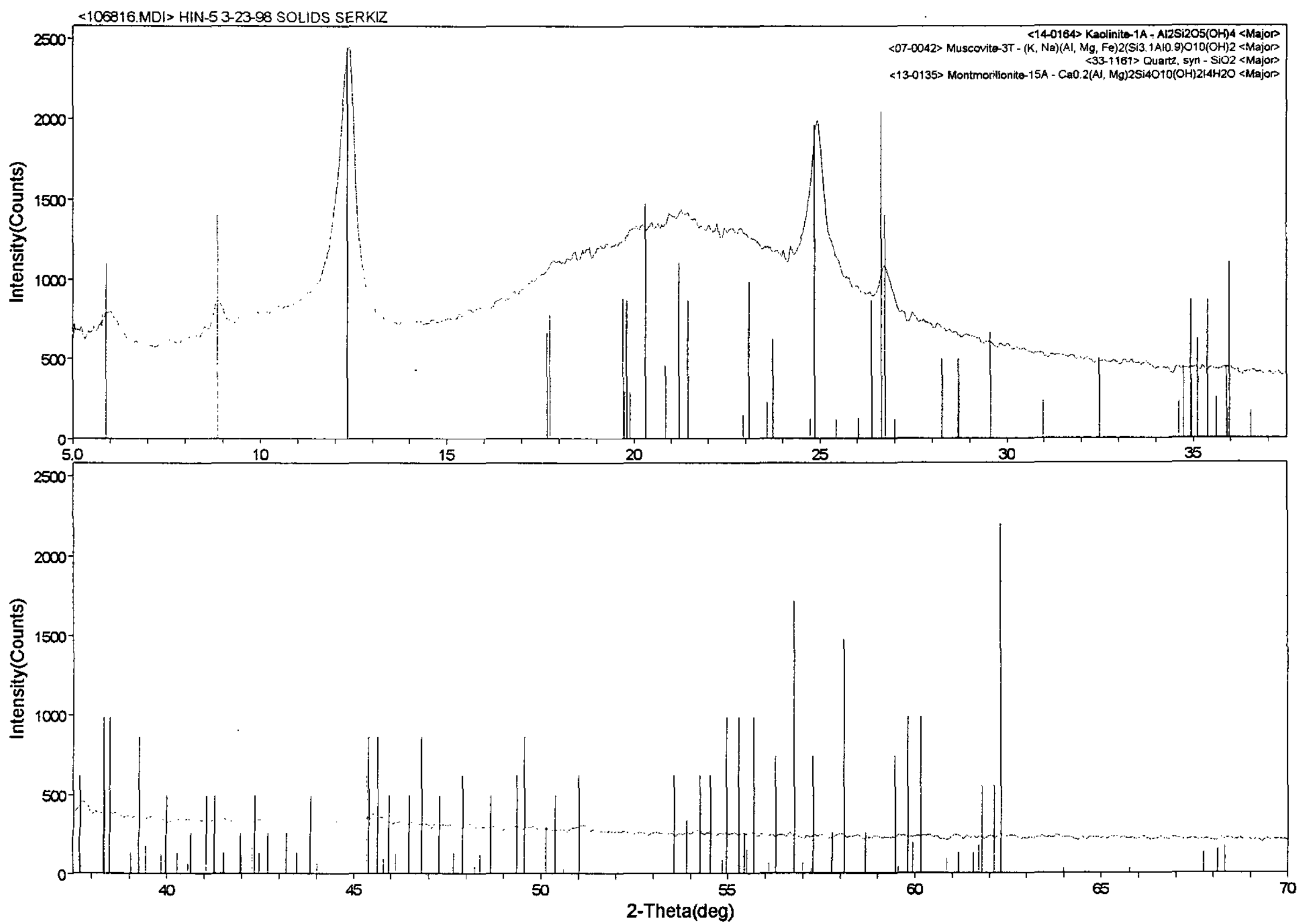

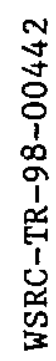



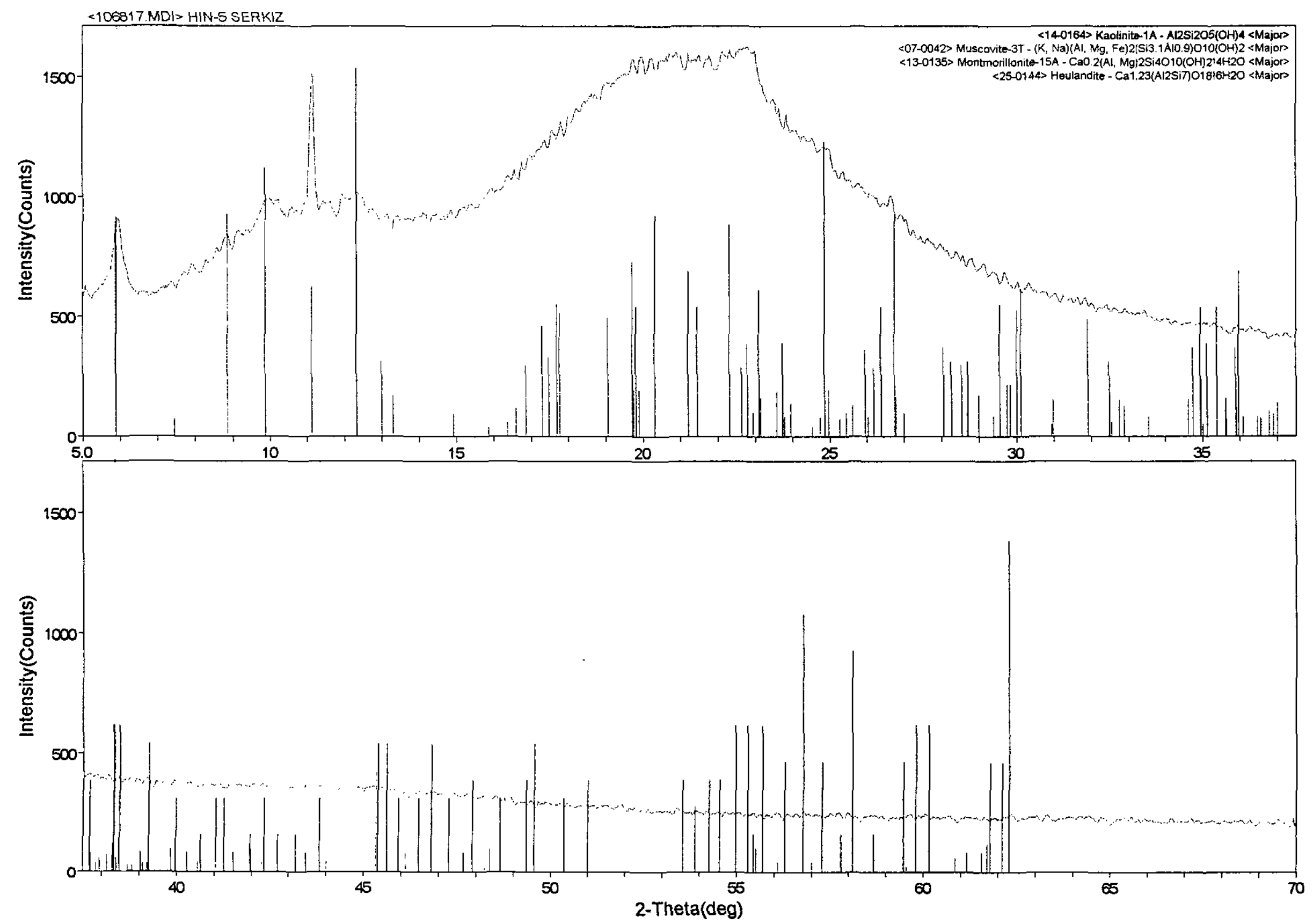

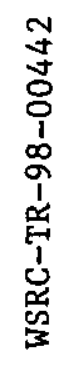



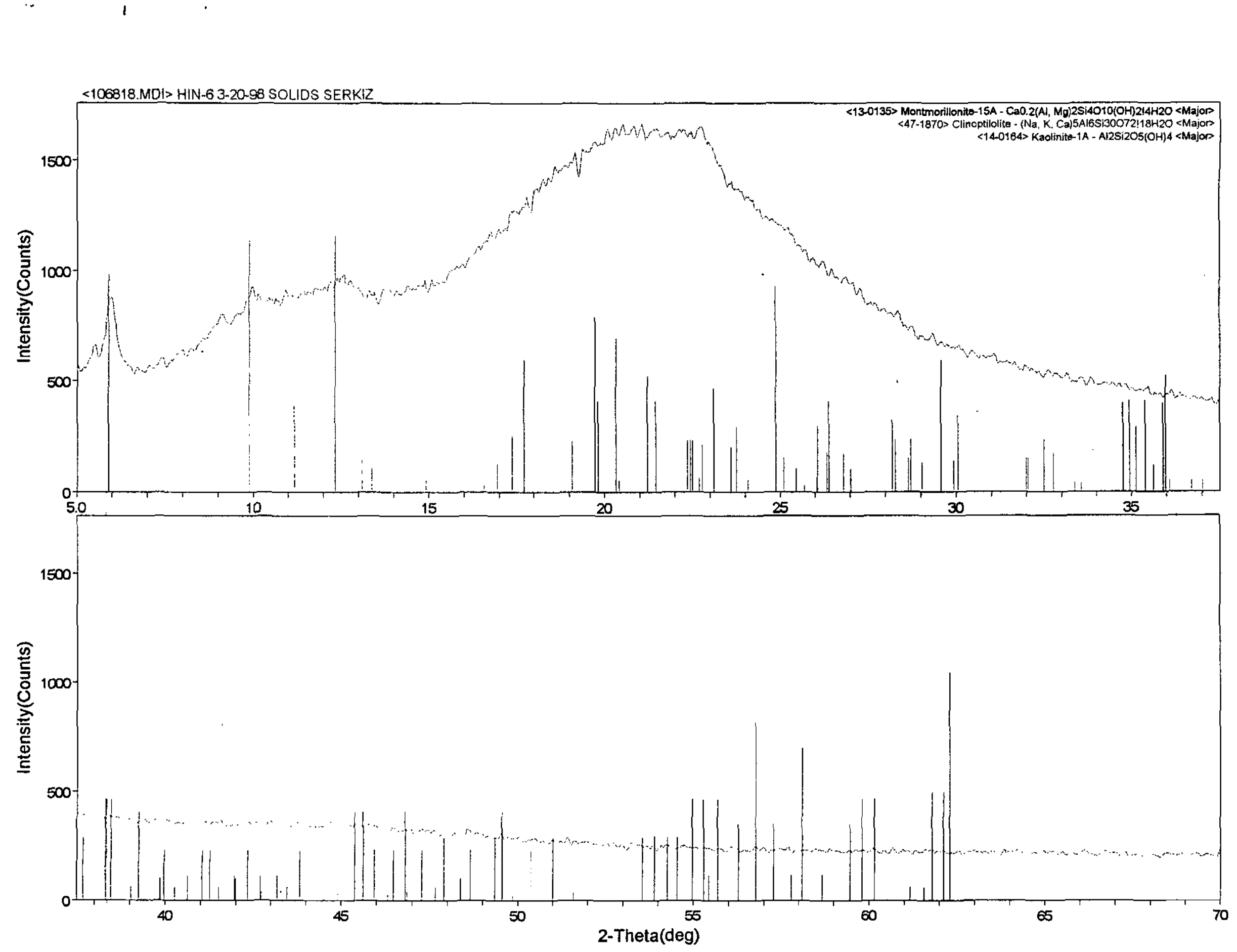

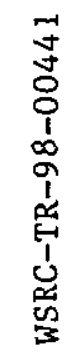




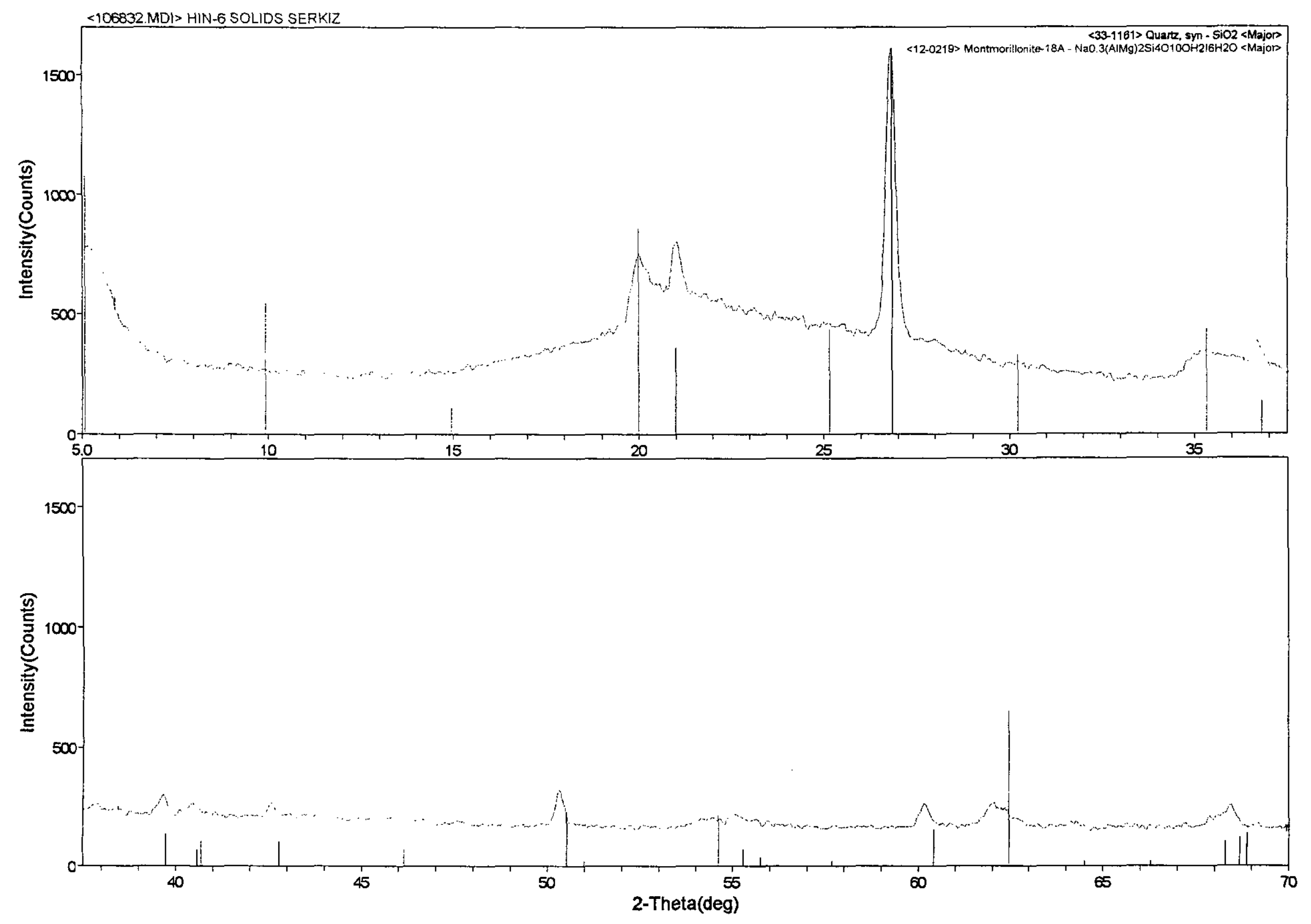

I
+
8
0
1
0
0
1
0
1
1
0
04
0
3 

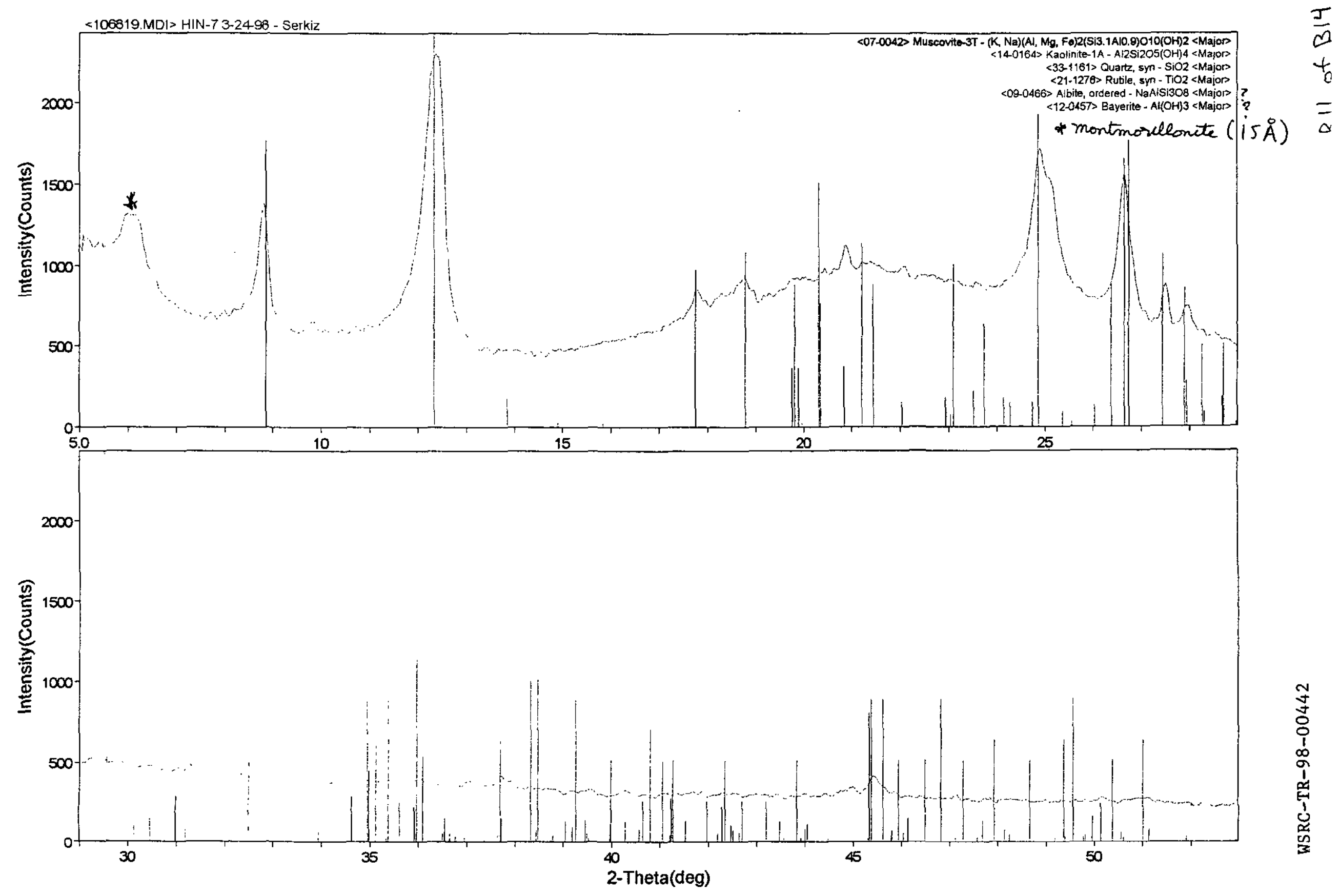


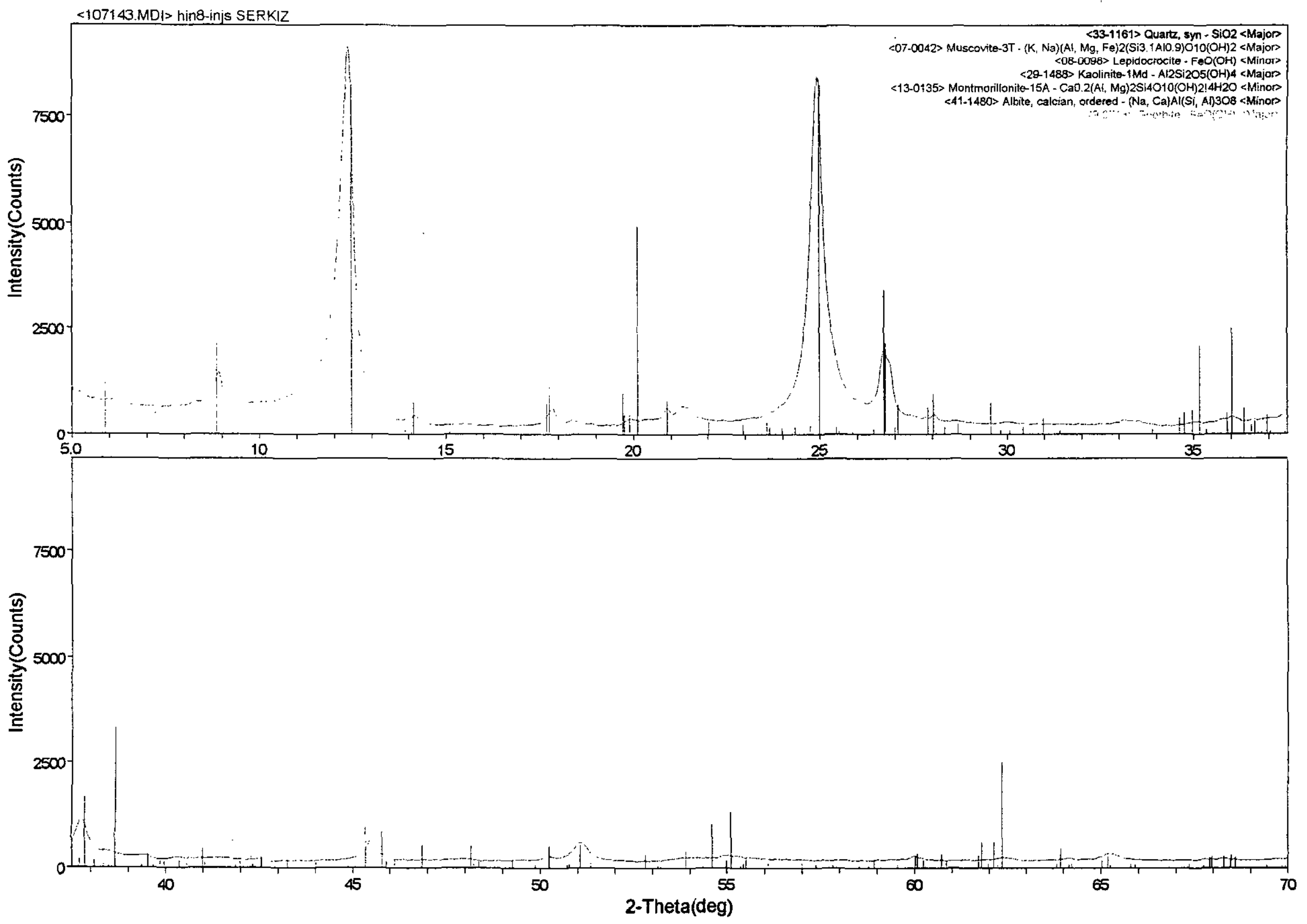



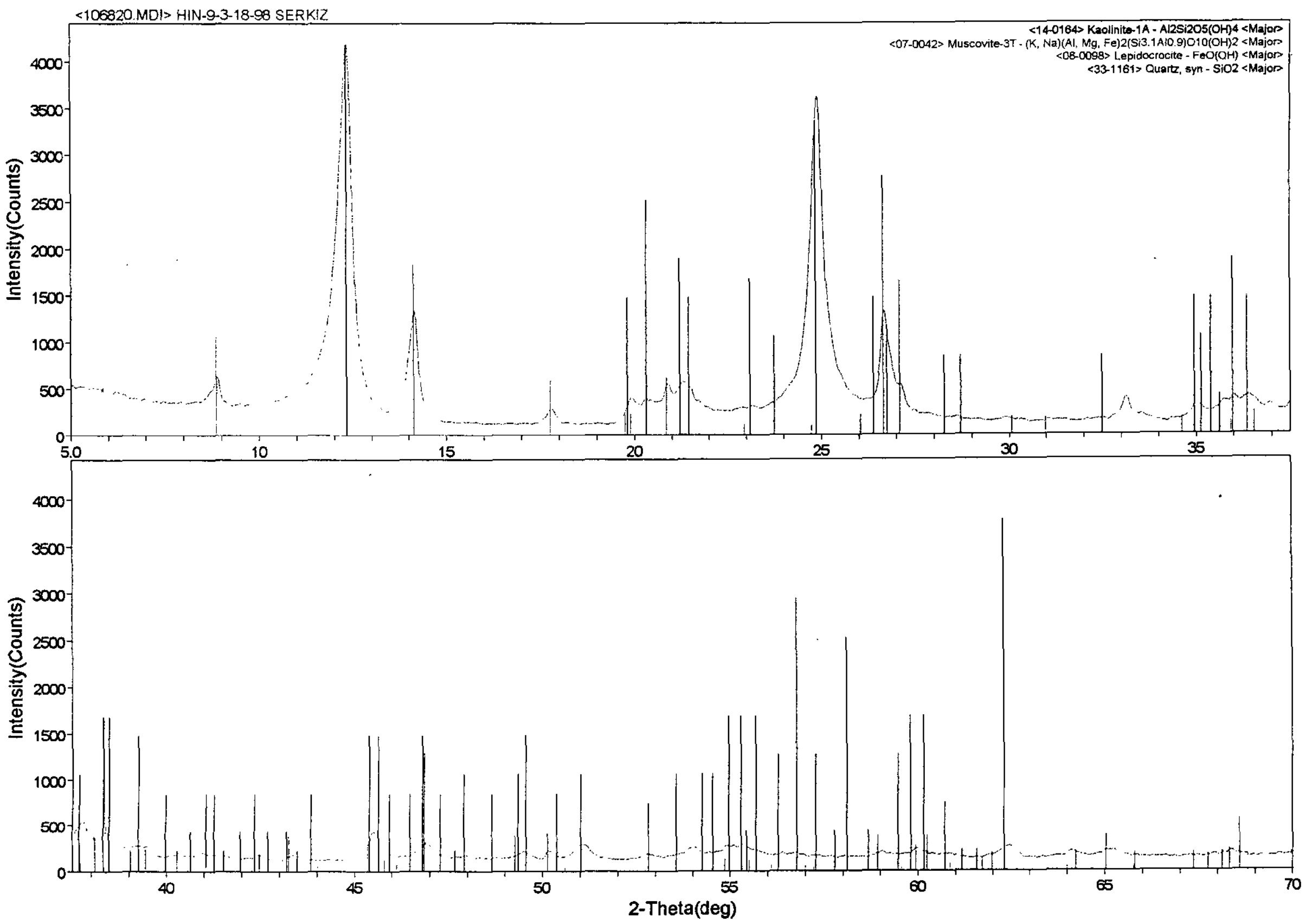

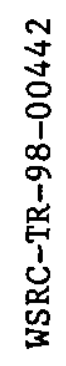




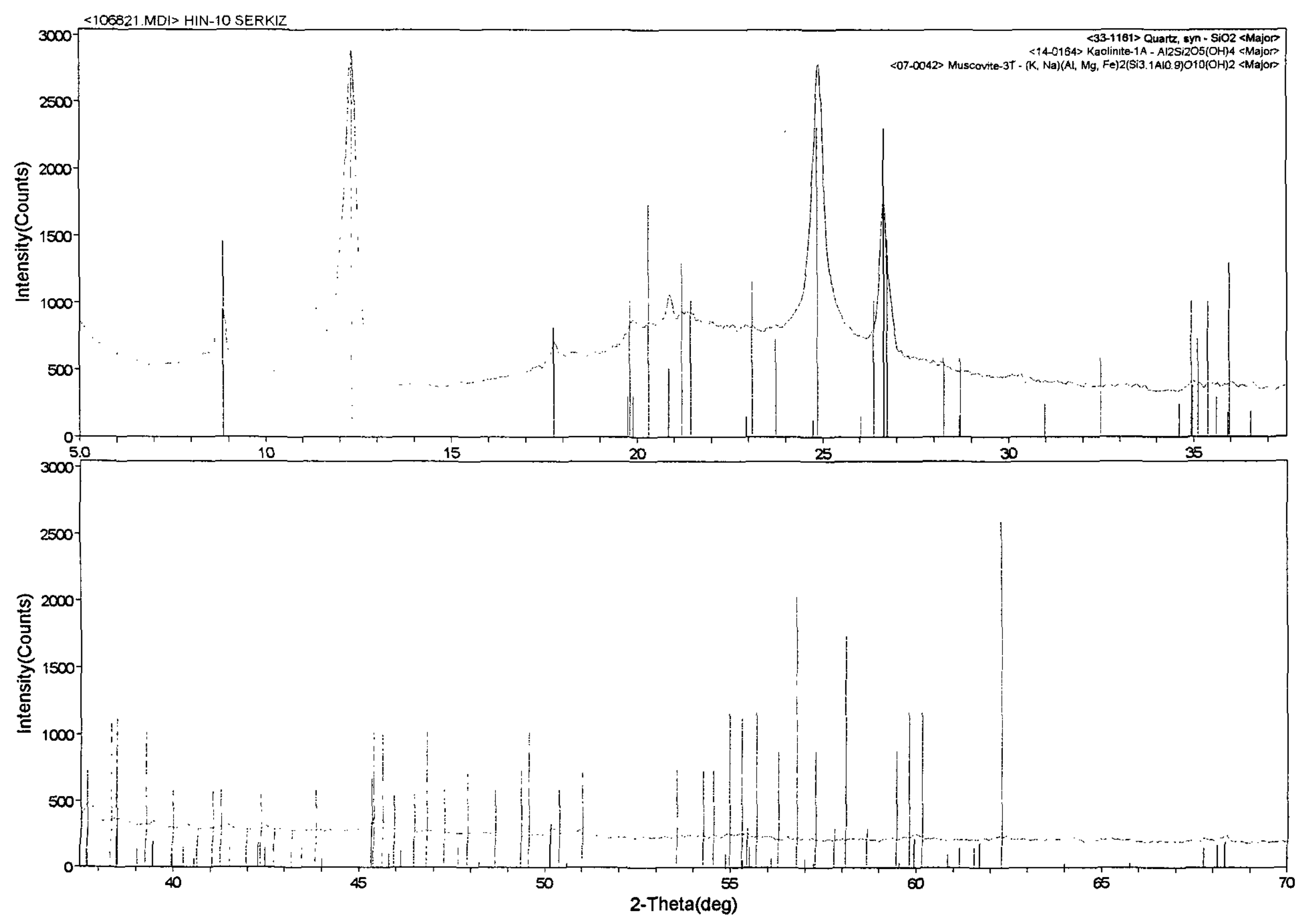

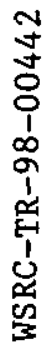




\section{APPENDIX C}

XRD Diffraction Patterns of Solids Collected from F- And H Area Seepage Basins Groundwater Remediation System Injection Tanks

March 1998 


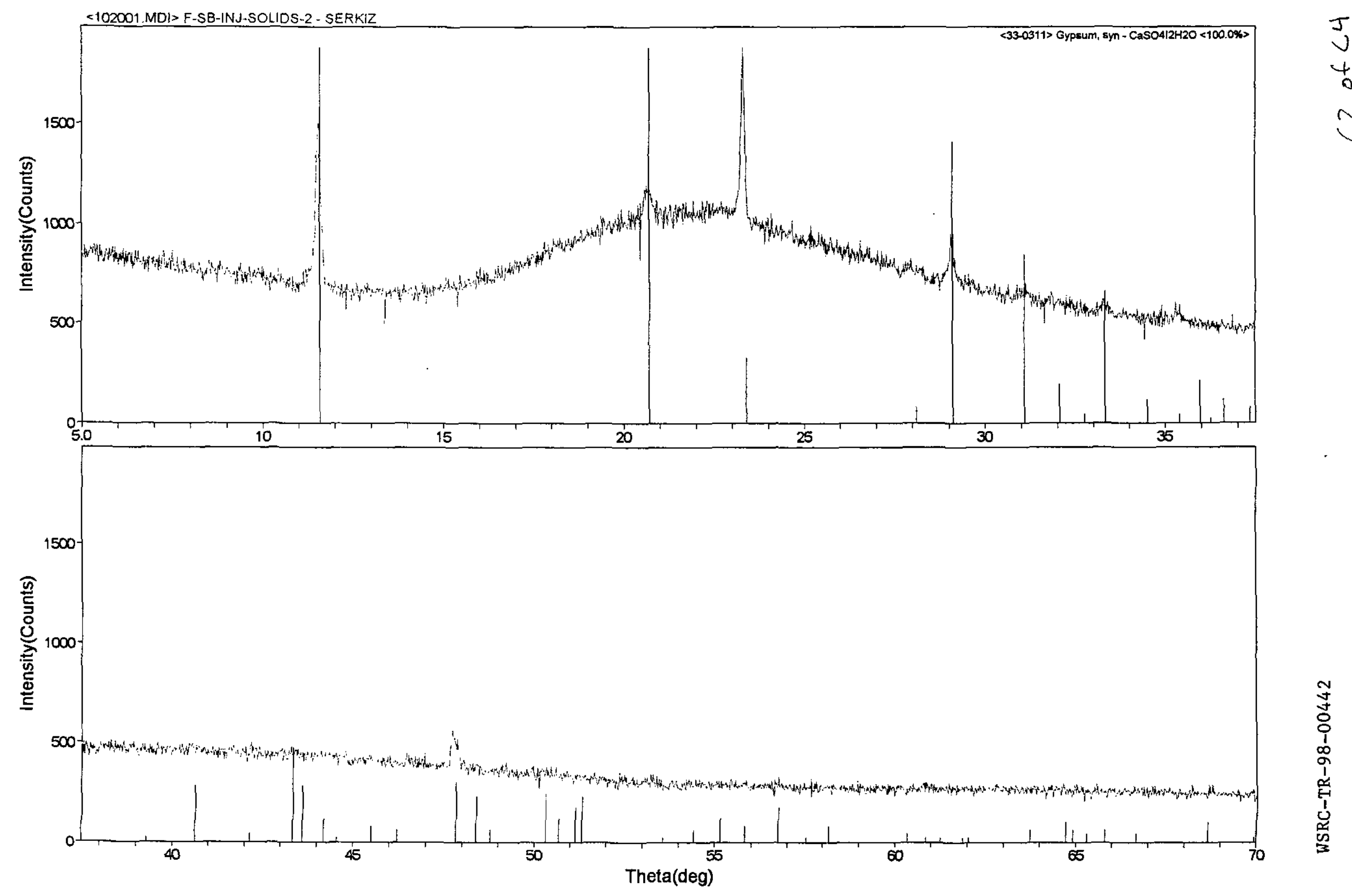



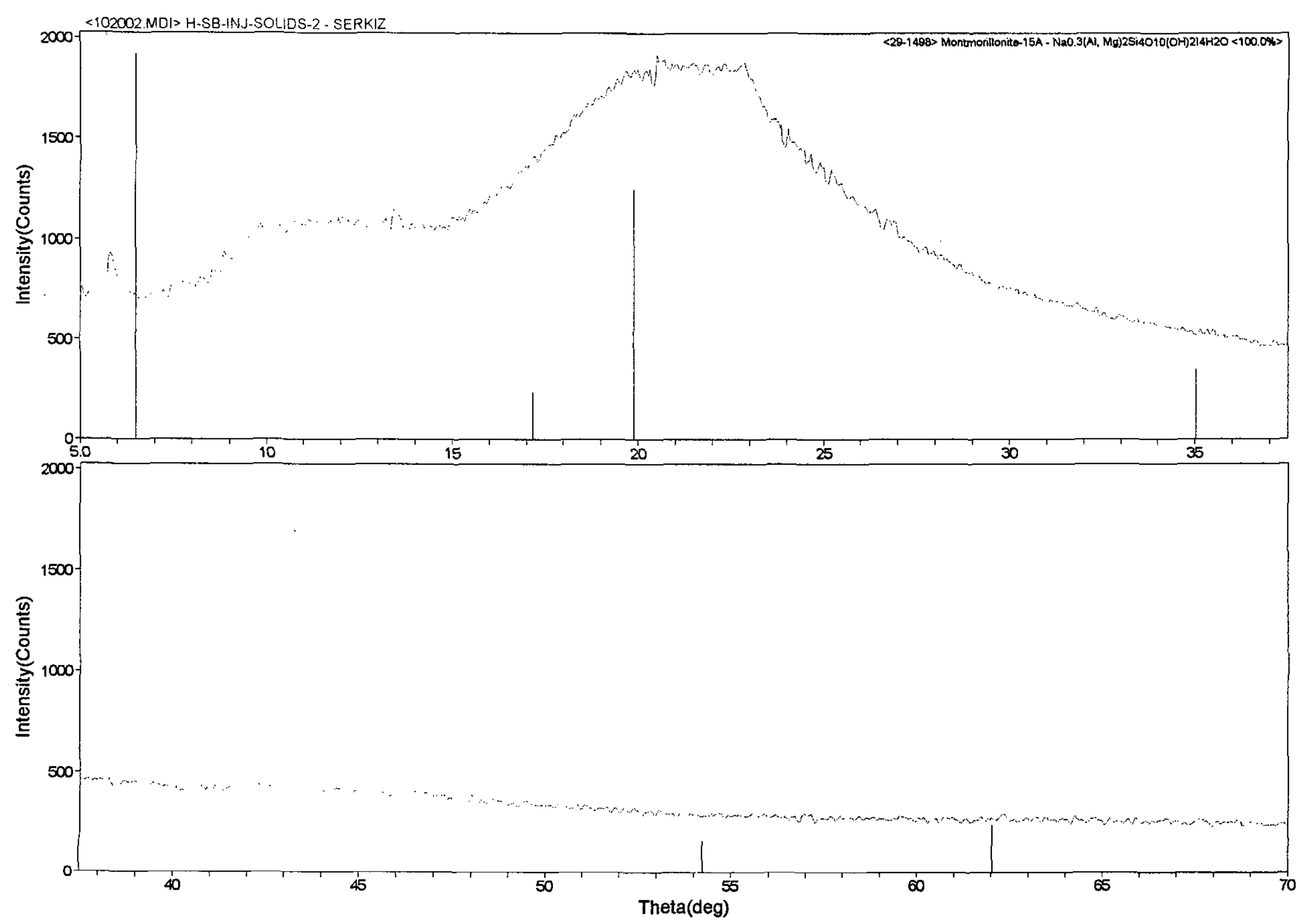

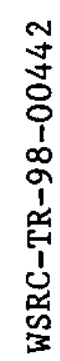




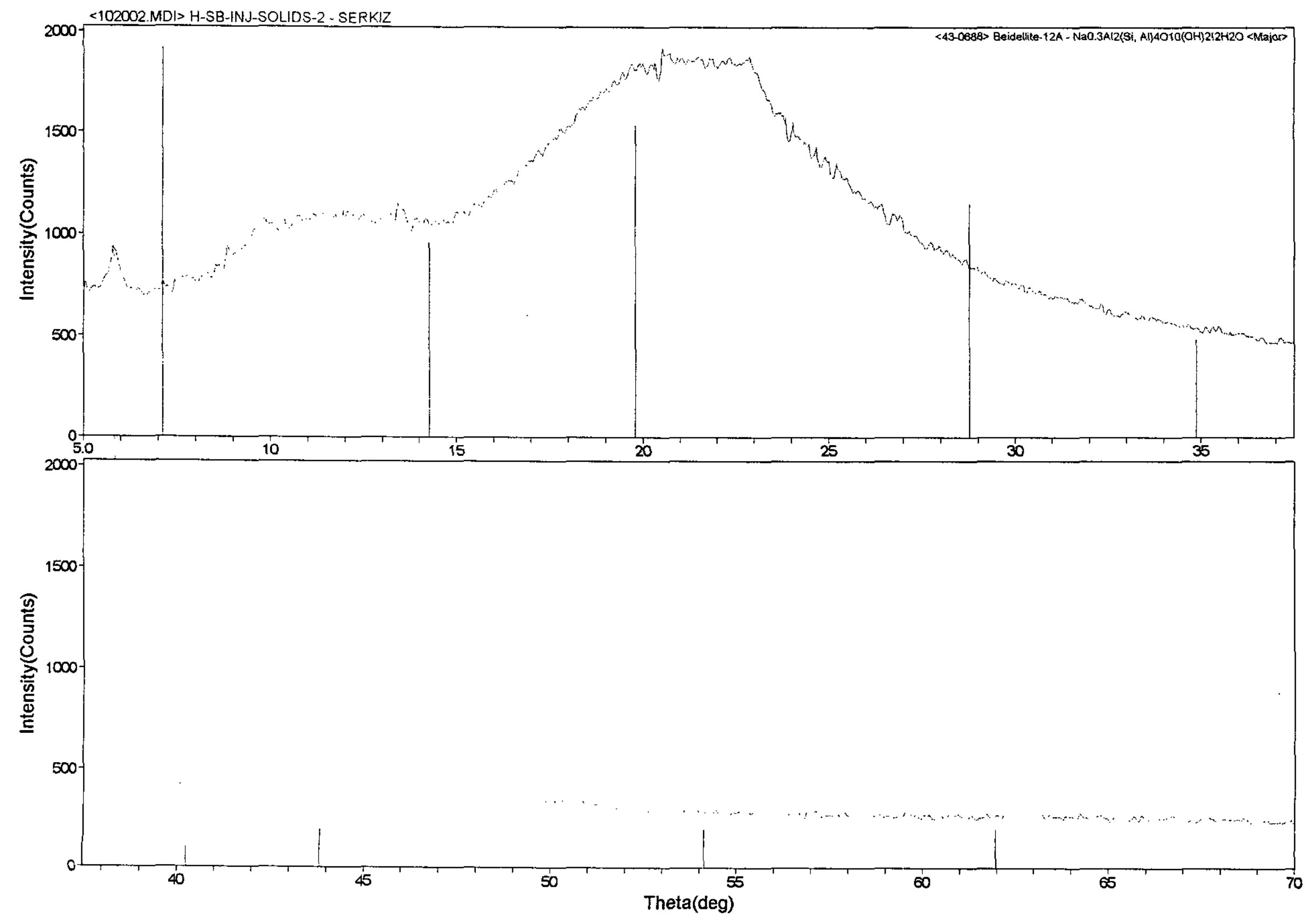

